\title{
The Epistemological and Ethical Value of Autophotography for Mobilities Research in Transcultural Contexts
}

\author{
DAVID BUTZ \\ Brock University, Canada \\ NANCY COOK \\ Brock University, Canada
}

\begin{abstract}
This article responds to calls from mobilities scholars for methodological innovation and reflexivity by (a) detailing our use of autophotography in a study of the everyday implications of a newly-constructed road for a small community in mountainous northern Pakistan, and (b) assessing autophotography's attributes as a visual/narrative method for mobilities research in that setting, on ethical and epistemological grounds. We demonstrate that autophotography's anti-objectivist epistemology of vision and participant-driven character, the portability and easy userinterface of compact cameras, and the inseparable mix of visual and narrative data the method produces, combined to attenuate epistemic injustice in our research, while also generating productive insights regarding the movements, representations and embodied practices our research subjects associate with the road. These points are developed with reference to literature on visual methods, mobile methods and subaltern autoethnography, as well as to the visual/narrative representations produced by study participants. The article concludes by exemplifying how research subjects used the road and its associated mobilities as discursive resources for the constitution of collective identity: to position their community in relation to modernity and tradition, to distinguish the community from its neighbours, and to articulate worries about the consequences of rapid social change.
\end{abstract}

KEYWORDS mobile methods; visual methods; autophotography; photo elicitation; autoethnography; epistemic justice; Gilgit-Baltistan; road construction; mobilities

The "mobilities turn" traces how mobility discourses, practices, and platforms shape socio-material realities by engendering movement and stasis in differentiated ways (Sheller, 2011, p.1). Scholars suggest effectiveness in this 
regard requires adapting and developing methods that access the activities, events, and meanings through which mobilities are socially instantiated (D’Andrea, Clolfi \& Gray, 2011; Hannam, Sheller \& Urry, 2006; Urry, 2007). A vibrant literature attempts to define the terrain of "mobile methods," suggest broad areas of methodological focus, and analyse the usefulness of specific "methods for mobilities research" (Sheller \& Urry, 2006, p. 2017; see also Büscher, Urry \& Witchger, 2010; Fincham, McGuiness \& Murray, 2010; Merriman, 2014; Manderscheid, 2014; Spinney, 2015; Warren, 2017). A sub-set of this scholarship focuses on visual methods (Cresswell, 2006; Hein, Evans \& Jones, 2008; Larsen, Urry \& Axhausen, 2006; Lorimer, 2010; Spinney, 2011). We contribute to this latter literature by detailing how we used a specific visual method, autophotography, and assessing its usefulness for mobilities research. Our argument has epistemological and ethical dimensions, which we develop in relation to epistemic justice and autoethnography.

Autophotography involves providing research subjects with cameras, asking them to photograph specified aspects of their lives, and collecting their oral explanations and interpretations of the resulting photos (Johnsen, May \& Cloke, 2008; Thomas, 2009). The method has three distinguishing features: it produces a combination of visual and oral data, it is participant-driven (Bryne, Daykin \& Coad, 2016; Ford et al., 2017; Mannay, 2010) in that visual productions are shaped by photographers' image-making decisions, and it may be employed on the move by participants who produce photos as they follow their daily routines.

We employed autophotography in an ethnographic project that investigates the social consequences of a newly-constructed road for residents of Shimshal, an agricultural community of about 125 households located in the Karakoram Mountains of Pakistan's Gilgit-Baltistan administrative unit (Figure 1). Shimshal's five hamlets are situated 60 kilometres into a tributary valley of the Hunza River. Until the mid-1960s, when the engineering corps of the Pakistani and Chinese armies began constructing the all-weather Karakoram Highway (KKH) to traverse the length of the Hunza Valley from Gilgit to the Chinese border at Khunjerab Pass, the region was accessible only by footpath or rough pony track (Khalid, 2011). Although Shimshal was farther from the main Hunza Valley than most villages, it was well-integrated into a regional pedestrian mobility regime. ${ }^{1}$ As sections of the KKH opened to vehicular traffic in the late 1970 s, communities along its route became subject to a new mobility regime, and those in side valleys began constructing link roads to access motorised transport (Kreutzmann, 1991; Wood \& Malik,

\footnotetext{
${ }^{1}$ This mobility system consisted of a network of footpaths and pony tracks, some located close to valley floors and others linking communities via mountain passes and high pastures. Low paths were used in winter, when streams could be forded easily; alpine paths were used in summer, when weather conditions were favourable. Travel between villages was infrequent until the late 1970 s, and limited mainly to adult men; most travel occurred among pastures and between the settlement and pasture zones within community territory.
} 
2006). By 1985, Shimshal - still three days' difficult walk from the KKH was one of only a few communities that remained remote from a new roadbased regional mobility constellation. In the early 1980 s, community leaders enlisted the support of the Aga Khan Rural Support Program NGO to build a link road to the village. ${ }^{2}$ Construction began in 1985; the road was completed 18 years later, in 2003, through a combination of volunteer labour and intermittent support from government and NGOs. Building the road was a staggering undertaking, which involved great individual and collective sacrifice; it is understood by many Shimshalis as the community's greatest display of unity and collective endeavour. After the road opened a three-day walk became a two-hour jeep ride with dramatic and socially uneven implications for mobility (Cook \& Butz, 2011, 2017).

We have been recording field notes and taking pictures related to the road's construction and use since our first trip to Shimshal in 1988, as aspects of previous ethnographic projects. In 2007 we obtained community permission to more systematically study the road. Our autophotography project was a component of that study, which also involved other qualitative and ethnographic methods. We employed autophotography partly in response to calls for innovative approaches that interrogate the structuring effect of mobilities discourses, practices, and platforms on social life more effectively than conventional conversational techniques. The prospect of participants taking away digital cameras and bringing back pictures and narratives shaped more by their patterns of movement than by ours seemed a promising way to understand shifting mobility discourses and practices in Shimshalis' everyday lives. We also hoped the method would enlarge the variety of Shimshalis we spoke with, provide another self-directed way for villagers to express themselves, and help situate participants' perspectives in everyday life spaces. Consequently, we initiated a small autophotography project in summer 2011, during which time 16 women and 35 men provided us with 344 narrativised photos. Autophotography proved to be well-suited for the mobility context we are studying, yielding a more productive process and richer results than we had anticipated.

\footnotetext{
${ }^{2}$ The Aga Khan Rural Support Program (AKRSP) is a branch of the Aga Khan Development Network, an international NGO connected to the Aga Khan, the spiritual leader of Ismaili Muslims, a large population of whom live in northern Gilgit-Baltistan. AKRSP was founded in 1982 to promote rural development in the region, and established a presence in communities by coordinating village and women's organisations through which savings, low-collateral loans, and agricultural extension could be arranged. Communities were encouraged to participate through the promise of a Productive Physical Infrastructure project selected by residents; Shimshalis chose a road. Due to the Shimshal road's scale AKRSP funded only a small portion of its cost.
} 


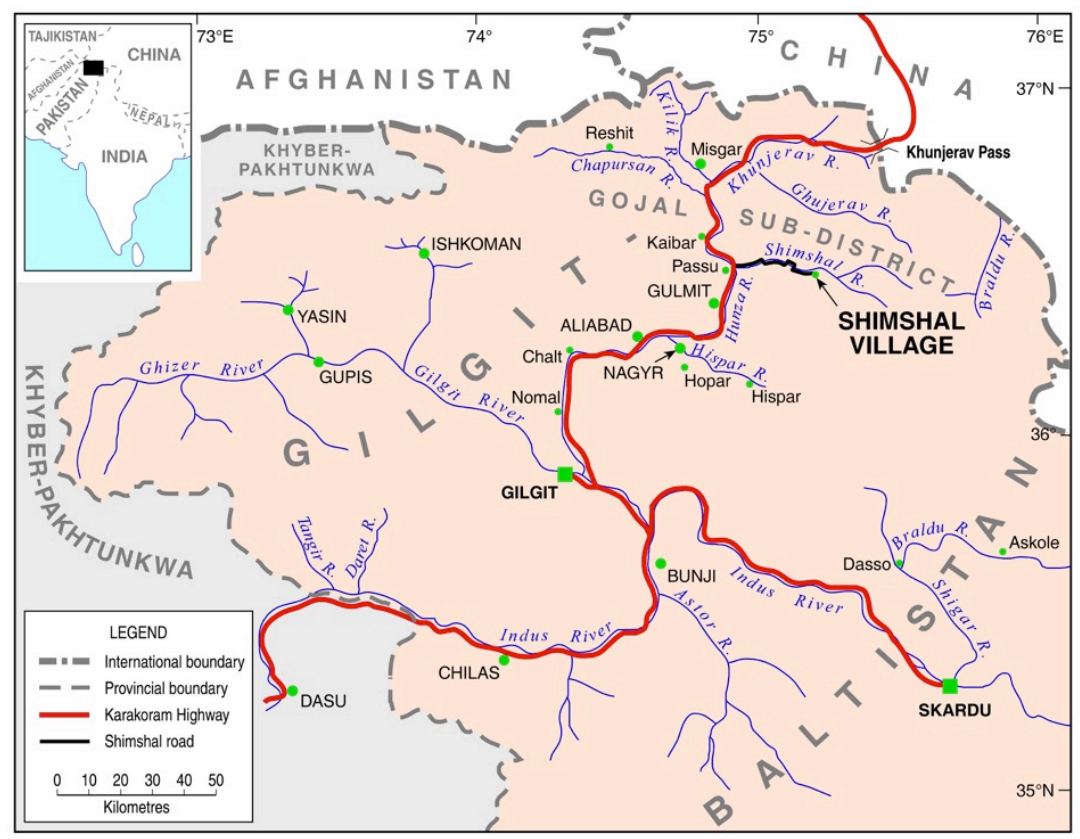

Figure 1. Location of Shimshal in Gilgit-Baltistan, Pakistan.

The paper begins by describing two dimensions of epistemic injustice testimonial and hermeneutical - and outlining how qualitative research may reproduce them, to emphasise their importance for research design. In our research context the lingering effects of colonialism present significant impediments to epistemic justice, so we propose an epistemology based in postcolonial theory - an autoethnographic sensibility (Butz, 2010; Butz \& Besio, 2004) - as a way to address the influence of colonial discourse on our research interactions and analyses. Epistemic justice and autoethnographic sensibility serve as conceptual resources for the paper's main section, which describes our use of autophotography, situates it in relation to mobile and visual methods, and assesses its epistemological and ethical efficacy as a visually-oriented method for mobilities. We differentiate autophotography from mobile methods that involve researchers moving with mobile subjects, and explain why it is preferable in our context. Developing this argument involves critiquing ethical claims to empowerment that are often associated with autophotography, as well as epistemological assumptions of accuracy, authenticity and closeness that surface in discussions of visual and mobile methods. We offer epistemic justice as a more appropriate way to frame autophotography's ethical benefits, and autoethnography as a more productive way to describe the epistemological characteristics of autophotography's visual/narrative yield. The article concludes by 
exemplifying how research participants used the road and its associated mobilities as performative resources for the constitution of collective identity.

According to social epistemologists, epistemic injustices take two forms: testimonial and hermeneutical. Testimonial injustice occurs when "someone is wronged in their capacity as a giver of knowledge" (Fricker, 2007, p. 7), for example, when they are excluded from speaking or granted less credence as a knowledgeable speaker because of context-specific prejudice or structural arrangements that undermine their capacity to be received as credible. All qualitative research risks testimonial injustice, through processes that define study populations, select samples, choose research sites, etc. Researchers frequently make decisions that are sensible in the context of a specific project, but which exclude or devalue the testimony of some prospective subjects for reasons of convenience or prejudice. Transcultural ethnographic research, for example, often privileges the testimony of English speakers, educated persons, and men. When whole bodies of academic knowledge are shaped by such credibility deficits and excesses, then the research process itself reproduces testimonial injustice, helping to create conditions for other axes of social injustice. Testimonial injustice is an important concern in our research context, where convenience conspires with local power structures to reduce our capacity to treat women, youth, uneducated and low status people as credible knowers.

Even more intractable is hermeneutical injustice, which transpires when "someone is wronged in their capacity as a subject of social understanding" (Fricker, 2007, p. 7). Hermeneutical injustice relates less to a person's lack of credibility as a knowledgeable agent than to their social intelligibility: their capacity to be understood on their own terms. It occurs when an individual or social group lacks communicative resources to articulate important features of their experience, or when an audience is unable to make sense of some people's self-articulations. In these instances a discursive community has failed to develop the vocabulary or concepts to render the experiences of some people intelligible, even to those who experience them (Medina, 2012). Even when speakers can express themselves in a manner that they find intelligible, their self-expressions may be nonsensical to their intended audience, because the latter's interpretive resources are insufficient for making sense of certain domains of experience.

Hermeneutical injustice is always a risk in qualitative research, because our efforts to understand research subjects on their own terms are hampered continuously by the mediating effects of our own pre-existing vocabularies, conceptual frameworks, ontological commitments, disciplinary conventions, etc., which often impose meaning on research subjects rather than accessing their own self-intelligibility. Moreover, subjects' efforts to express themselves - especially transculturally - may be similarly hampered by a lack 
of adequate vocabulary or conceptual resources to describe certain categories of experience, or by other power differentials inherent to specific research relationships that render them mute, incoherent, or unintelligible.

Although testimonial injustice may arise from individual prejudice it is often structural (Anderson, 2012). Hermeneutical injustice is always structural, because it results from the epistemic characteristics of a discursive formation, which exceed individual communicative transactions. Colonialism, for example, provides a backdrop in our research context for contemporary testimonial and hermeneutical injustices, even as it is reproduced by them (Butz \& Besio, 2004). The epistemic effects of colonial discourse are evident in the exaggerated authority of Western knowledge modalities for both researchers and local subjects, the transcultural power relations that saturate the research field, and the tendency in development discourses and elsewhere to treat locals as "Native Informants" (Spivak, 1999, p. 113), rather than reflexive knowers. Undermining such outcomes involves tracing their effects on transcultural knowledge production. Understanding subjects' utterances and crediting them as knowledge requires considering how they are shaped by a global field of imperial power and its enactments in research interactions. Postcolonial scholarship is helpful for this, especially Mary Louise Pratt's formulation of autoethnography, which refers to:

instances in which colonised subjects undertake to represent themselves in ways that engage with the coloniser's own terms. If ethnographic texts are a means by which Europeans represent to themselves their (usually subjugated) others, autoethnographic texts are those the others construct in response to or in dialogue with those metropolitan representations... autoethnography involves partial collaboration with and appropriation of the idioms of the conqueror. (1992, p. 7; emphasis in original)

Elsewhere she adds:

Autoethnographic texts are not...'authentic' forms of self-representation... Rather they involve a selective collaboration with and appropriation of idioms of the metropolis or conqueror. These are merged or infiltrated to varying degrees with indigenous idioms to create self-representations intended to intervene in metropolitan modes of understanding. (1994, p. 28; emphasis in original)

Pratt describes autoethnography as "the struggle for interpretive power" (Jean Franco paraphrased in Pratt, 1999, p. 39), which for colonised populations necessitates "produc[ing] oneself as a self for oneself" simultaneous "to produc[ing] [one]self as an 'other' for the coloniser" (1999, p. 39).

Pratt focuses on textual communications in colonial situations, but autoethnographic expression applies to many contexts structured by historical relations of domination, our research site among them; we think it describes a characteristic mode of transcultural self-representation in these situations (Butz, 2010; Butz \& Besio, 2004). Conceptualising Shimshalis' interactions 
with us as autoethnographic helps to avoid epistemic objectification (Fricker, 2007, p. 133): treating subjects as Native Informants rather than producers of knowledge. Autoethnography provides a discursive frame for understanding subjects' communicative interactions with us, imagining purposes in their self-expressions, and interpreting them as knowledge-producing endeavours in which locals and researchers are simultaneously subjects and objects of knowledge. An "autoethnographic sensibility" (Butz \& Besio, 2004) constitutes a mode of analysing our involvement in this communicative process and helps us appreciate our responsibilities to respondents' selfrepresentations; it is a form of critical reflexivity.

Three practical imperatives follow. First, as autoethnographic expression is an interventionary effort by people subordinated in an uneven discursive field, we have a responsibility to listen analytically for the autoethnographic characteristics of research subjects' self-expressions to us and other metropolitan agents that impinge on their lives. Such attentiveness is not just a tool for researcher reflexivity, but also a resource for analysing how transcultural interactions shape subjects' identities and lives. Second, an appreciation of autoethnography requires us to support subjects' efforts to intervene intelligibly and credibly in metropolitan modes of representation. This applies most obviously to our own analyses, but also to autoethnographic projects unrelated to our research, for example by working to amplify locals' transcultural voices or helping locals perfect an idiom that renders their perspectives meaningful to metropolitan audiences. It also inspires us to build our research around communities' autoethnographic projects. Third, attentiveness to autoethnographic communication encourages us to employ data generating methods that enhance the autoethnographic characteristics of locals' transcultural communications with us, and modify them to enable locals to express themselves intelligibly and subtly in an autoethnographic register.

Together these aspects of an autoethnographic sensibility provide an epistemological framework for our transcultural research practice and practical strategies for addressing the testimonial and hermeneutical dimensions of epistemic justice. They are considerations in our methodological choices, including incorporating autophotography into our investigation of road construction and mobility in Shimshal. Consequently, our assessment of autophotography as a visual/narrative method for mobilities research below involves evaluating its effectiveness in relation to these ethical and epistemological priorities. First, however, we situate autophotography in relation to discussions of mobile and visual methods.

Mobility scholars argue that understanding movement's import for individuals and social relations requires developing new approaches for apprehending mobile cultures, practices, and meanings. Although many 
techniques are suggested, emphasis is placed on "mobile methods," approaches used on the move to "capture, track, simulate, mimic, parallel and 'go along with"' mobile subjects, objects, images, and ideas in motion (Büscher, Urry \& Witchger, 2011, p. 7; Larsen, Urry \& Axhausen, 2006). Explanations for this methodological focus stem from the claim that movement is a fleeting, materially-embedded, embodied, and experiential phenomenon, which cannot adequately be represented using conventional cognition-oriented methods. Authors assert that accessing "the more intangible and ephemeral meanings of mobility" (Spinney, 2009, p. 826) requires moving with research subjects: participating kinaesthetically in their movement experiences, eliciting their commentary in specific mobility contexts, and observing practices and spaces of movement that would be inaccessible via verbal or textual representation alone. Moreover, by enabling researchers to experience particular mobilities in situ, mobile methods are understood to promote greater sensitivity to how the attributes of place shape and are constituted through movement (Hein, Evans \& Jones, 2008).

Much methodological innovation associated with mobile methods involves vision and visuality. Motion and vision are understood to be closely intertwined (Büscher, 2006; Murray, 2009; Pink, 2008), because visual recognition is an organising dimension of sensorial experiences of movement (Phillips, 2005). Therefore, "moving with" methods enable researchers simultaneously to see the mobile world subjects see and to observe them in it. Moreover, vision is an aspect of kinesthetic and affective mobility experiences that may be recorded and replayed to evoke enactments or contexts of movement.

Historically, visual representation was used by social scientists mainly to offer empirical flavour or back-up to accompanying text. Photographs, paintings, sketches, and maps were presented as authoritative and objective portrayals of a time and place, despite being composed according to certain interests and pictorial conventions (Lutz \& Collins, 1993). Visual representation fell out of favour among social scientists in the $20^{\text {th }}$ century's latter half, first as positivist perspectives rejected the validity of visual data (Packard, 2008, p. 65), and later as critiques associated with the crisis of representation made the supposed objectivity and transparency of visual representation untenable, and feminist and postcolonial scholars diagnosed the visual gaze as complicit in colonial appropriation, the subjugation of women and other projects of domination (Gilman, 1986; Gregory, 2003; Lewis, 1996). As Mike Crang notes (1997, p. 368), "academia and photography do not walk innocently in the world. Hovering in the background is the shade of some panoptic apparatus, recording, surveying and disciplining bodies."

Recent calls to reintroduce visual methods respond to poststructural critiques of "pure vision" (Kearns, 2000, p. 338) by approaching visual representation as a social practice shaped by the intentions, aesthetic sensibilities, ideological commitments, and spatio-temporal contingencies of 
creators and viewers, rather than simply as a technologically-mediated way to present facts on a landscape. Some mobility scholars think this antiobjectivist approach to visuality aligns well with the mobility turn's emphasis on the affective, experiential, practiced character of mobility, which helps explain the emergence of visual mobile methods. However, epistemological challenges remain. As noted by Peter Merriman (2014), in much of the mobilities literature there lingers a dubious implication that the participatory character of mobile methods enables researchers to more "accurately interpret, represent and understand a world increasingly constituted in mobilities" (Fincham, McGuiness \& Murray, 2010, p. 5). Similar problematic claims to accuracy and authenticity appear in rationales for using visual methods in mobilities-oriented and other research (Guell \& Ogilvie, 2015). This deployment of visually-oriented mobile methods to gain more accurate or authentic understandings risks contradicting the epistemological foundations (a) of mobile methods, in non-representational and postfoundational theory, and (b) of visual methods, in an approach to visual artefacts as discursively organised to produce particular representational and self-representational effects, including that of accuracy or realism.

One of our challenges was to exploit the advantages of visually-oriented methods for studying mobilities without succumbing to the epistemological shortcut of associating visuality or participation with accuracy. Our decision to employ autophotography - a visual method but not a mobile method in the moving-with sense - responded to this challenge, while also addressing other ethical and epistemological concerns. Our research involves living in Shimshal with a local family for extended periods, so we participate continuously in the mobile practices and rhythms of village and household life. These immersive, embodied experiences of mobility are important sources of insight, but they are also limiting and selective in ways that would not be overcome by formalising them in an explicitly mobile method. The village has many important spaces of mobility that we simply cannot have embodied access to, including certain domestic and religious spaces, and spaces that are gendered in particular ways. A participatory mobile method would not provide us with embodied access to these spaces or the practices that occur there, even though there is no prohibition on locals telling us about these spaces and aspects of the things that happen in them. Certain other village spaces are accessible to us, but not with certain categories of Shimshali subject (young women especially), whose reputation would be jeopardised by being co-present there with a foreigner. This tells us something about the socially differential nature of motility in Shimshal (see Warren, 2017), but also means that go-along methods would systematically exclude certain groups of Shimshalis from participating in our research. Again, members of those groups may show us photographs or talk to us without constraint; it is a particular context of embodied co-presence that is socially dangerous. 
We also worry that go-along methods would be experienced as intrusive and embarrassing for some Shimshalis, with unhelpful epistemological effects on their representations as well as negative implications for epistemic justice. As outlined above, we understand Shimshalis' interactions with us to be autoethnographic, and think it is important to help create the conditions for rich autoethnographic expression. Participatory mobile methods that involve moving with research subjects through the Shimshal landscape may be effective in this regard if those subjects are our close Shimshali friends or village elites; with most prospective participants they would produce a context of awkwardness or embarrassment that would limit their capacity to represent themselves or their village effectively (i.e., to their satisfaction) in an autoethnographic register.

Finally, moving-with methods have been criticised for "focus[sing] on mobile and active subjects at the expense of a broader understanding of materialities, practices and events" (Merriman, 2014, p. 169), which are also important features of a mobile world. The mobility implications of road infrastructure exceed embodied and affective experiences of movement itself: landscapes are reshaped, new artefacts are introduced, and social relations, identities and community discourses are reconstituted. Mobile methods can interrogate some of these implications, but not necessarily more effectively than conventional methods, and not without epistemological and ethical costs. We hoped autophotography would afford some of the benefits of including Shimshalis' visual representations in our study without exposing our research to the disadvantages of approaches that would involve us moving with research participants.

Autophotography is one of several visual methods that have become popular since the 1990s, including in mobilities research. Its multiple names self-directed photography (Aitken \& Wingate, 1993), photo-elicitation (Harper, 2002; Mandleco, 2013), and photovoice (Bananuka \& John, 2015; Wang, 2006) - indicate several variations, which nevertheless share three epistemological characteristics: (a) they employ an anti-objectivist epistemology of vision; (b) they generate visual-narrative data through a subject-oriented process; and (c) they utilise portable photographic technology. In what follows, we interrogate these characteristics, explain why they are well-suited for mobilities research, and describe our use of the method.

Autophotography expands the focus of visual research from visual artefacts to visuality: the network of "picturing practices" (Crang, 1997) that shape the production and reception of artefacts and give them meaning in particular contexts (Crang, 2010; Rose, 2007; Thomas, 2009). ${ }^{3}$ This is an anti-

\footnotetext{
${ }^{3}$ The term "picturing practices" emphasises the contextual action involved in seeing, framing, showing and viewing, which highlights photography "as practice rather than representation, as taking part in the world rather than reflecting it" (Crang, 1997, p. 360). As Crang (p. 362) argues, "images are...parts of practices through which people work to establish realities... [they] are not
} 
objectivist epistemology of vision, where visual artefacts are less important as sources of knowledge than the practices of visuality that surround them, and more useful when examined in relation to this broader context. Autophotography generates a mix of visual artefacts and associated picturing practices by asking research subjects to produce photographs that relate to a specified object of inquiry and then provide verbal commentaries on them. This combination of photographs and narratives, accompanied by observations and descriptions of the compositional process, helps researchers learn how subjects produce visual representations in specific contexts, what images they produce in relation to the object of inquiry, why they produce the pictures they do, how they interpret them, and how they use them as social resources (Johnsen, May \& Cloke, 2008). The key is a participant-oriented process that allows photographers to shape their representations according to their own interests and circumstances (Belin, 2005; Mannay, 2010). The resulting visual/narrative productions are valuable precisely for their subjectivity: their rootedness in particular interests, perspectives, aesthetic preferences, and contexts of reception.

Researchers find these epistemological characteristics helpful for appreciating subjects' complex, materially-grounded experiences and interpretations of their social worlds, as evidenced by the method's use in researching constructions of the self (Kohon \& Carder, 2014; Phoenix, 2010), the relationship between place and everyday life (Dixon \& Hadjialexiou, 2005; Lombard, 2013), students' negotiations of educational institutions (Clark-Ibáñez, 2004; DeMarie, 2010), experiences of immigration and belonging (Faber, Moller \& Pristed Nielsen, 2013; Streng et al., 2004), interpretations of health and disability (Booth \& Booth, 2003; Carnahan, 2006), commuting practices (Guell \& Ogilvie, 2015), and travel behaviour (Guell, Panter, Jones \& Ogilvie, 2012).

In this empirical literature autophotography and its variations are described as techniques through which visuality may be used to expand on insights provided by more strictly conversational, observational or participatory methods (Castleden, Garvin, \& Huu-ay-aht First Nation, 2008; Johnsen, May $\&$ Cloke, 2008). Authors frequently emphasise that autophotographic data "captures" or uncovers "real" experience, provides a "more complete and complex picture" of reality, and together with other methods contributes to an analytical strategy of triangulation (e.g., Guell \& Ogilvie, 2015, pp. 215, 201, 214). These claims attribute a factuality to subjects' photos and narratives, which is at odds with an anti-objectivist visual epistemology. Arjun Shankar (2016, p. 158) argues that "the uncritical use of photovoice has allowed a kind of reinvigoration of a positivist orientation toward authenticity, in the idea that the 'true story' comes through a community's images and words." Shankar (2016, p. 184) fears that the result "will only serve to reinforce

so much counterposed to reality as a route through which worlds are created"; in other words, they are autoethnographic, ways of producing a self for the self as well as for others. 
stereotypical imaginings of marginalised peoples facilitated by the positivist trap of an image as 'mere description"' and suggests approaching subjects' photos as aesthetic productions through which image-makers are understood to be producing, not reflecting realities. Our strategy of treating the image/narrative-making process as autoethnographic addresses the same epistemological issue as Shankar's focus on aesthetics: autophotography's reality-producing effects.

Autophotography's participant-orientation is also understood to have ethical benefits, which are often framed in terms of empowerment, particularly a shift of representational power from researchers to research subjects (Padgett et al., 2013; Shah, 2015). Indeed, empowerment of subjugated groups to "define, analyse and critique their communities through photographs and the analysis of photographs" (Joseph, 2017, p. 293) is often identified as autophotography's central motivation and defining characteristic (Delgado, 2015; Johnson, 2011). Consistent with these empowermentoriented assertions, much autophotographic research has focused on indigenous groups (Castleden, Garvin, \& Huu-ay-aht First Nation, 2008; Kaplan 2015), youth (Corcoran, 2015; Sensoy, 2011; Zehle, 2015), impoverished or homeless people (Bukowski \& Beutow, 2011; Dixon \& Hadjialexiou, 2005; Johnsen, May \& Cloke, 2008), and others whose perspectives are under-represented in scholarly and public discourse (Belin, 2005; Booth \& Booth, 2003; Mannay, 2010; McIntyre, 2003).

Some studies problematise claims that autophotography empowers research subjects (Allan, 2012). For example, Josh Packard (2008) found that his homeless male subjects' technical ineptitude with cameras, seeming lack of familiarity with pictorial conventions that would help make their photos intelligible to viewers, and paucity of "confidence or capital needed to communicate their knowledge" verbally (2008, p. 73) conspired to attenuate the empowerment-effect he anticipated. Packard (2008, p. 74) concludes that his attempt to "giv[e] voice to the voiceless was undermined because of the extreme marginality of [his] participants and the inherent power discrepancy between a housed researcher and the homeless participant." Other authors reject the notion of empowerment through participatory methods altogether, associating the claim with neoliberal ideologies of responsibilisation and crude theories of power, and questioning assumptions that participatory methods enable more truthful or agential expression (Alejandro Leal, 2007).

To imagine that empowerment is achieved by ceding representational control supposes "that people who wield power are located at institutional centres, while those who are subjected to power are to be found at the local or regional level - hence the valorisation of 'local knowledge' and the continued belief in the empowerment of 'local' people through participation" (Kothari, 2001, p. 140). The discourse of empowerment through participation overlooks how power relations organise the local, and how participatory techniques can articulate local knowledge in ways that reproduce local power structures. Members of subordinated groups may feel compelled to articulate norms that 
reassert established hierarchies, thereby legitimizing local knowledge in ways that perpetuate their subjugation. A Foucauldian understanding of power is better-suited for our Shimshal research, which occurs within a web of social relations structured by multiple powers, where our own capacity to exert influence at the local scale rarely exceeds our research participants' and hosts', despite our privileged positioning in global relations of knowledge production. The power we exercise in research encounters and on local selfrepresentations is neither discrete enough nor sufficiently-located in our own agency to be within our power to relinquish or redistribute. We cannot expunge our influence or that of powerful local actors and discourses from subjects' self-representations, or offer them speaking positions outside the field of power through which they are constituted. We cannot, therefore, anticipate empowerment.

We find it more plausible to frame autoethnography's ethical attributes in terms of the testimonial and hermeneutical dimensions of epistemic justice. Although there is little we can do to change internal power dynamics that reproduce testimonial injustice within the village, we can reduce the extent to which our research perpetuates testimonial injustice against certain groups by employing methods that Shimshalis from a variety of subject positionings are likely to engage with willingly, comfortably, and with a sense of competence. Go-along mobile methods do not satisfy these criteria, as they exclude certain groups of Shimshalis from participating altogether. Conventional interviewing methods are also deficient in this regard; villagers associate interviews with household surveys and fact-seeking interrogations employed by development agencies, and community discourses frame the authoritative knowledge these external actors seek as the domain of village elites. Consequently, most Shimshalis are reluctant to participate in formal interviews, and nervous of overstepping their representational authority when they do.

Photography has fewer constraining connotations in Shimshal. Its practice is not strongly-associated with village elites; nor are preconceptions evident regarding who should take photos and discuss them with us. It is most closely-associated with village youth, whose perspectives are often excluded from research on Shimshal. Men are more likely than women to be familiar with cameras, but there is no social constraint on women using photographic technology, and the photos our female subjects produced were as technicallycompetent as those produced by men. Still, despite concerted efforts to recruit female subjects, fewer than half as many women than men participated, for two main reasons: women's daily household work leaves little free time to take photos and talk about them; and some women lack the social confidence (or support from male family members) to contribute their perspectives to research in any form. Gender disparity in our sample remains a site of 
testimonial injustice, which we did not fully overcome. ${ }^{4}$ Nevertheless, our sample was more varied in terms of age, social positioning and gender - and less-crowded with community elites - than more conventional conversational methods or more innovative mobile methods would have allowed. Our four young research assistants (two men and two women) recruited subjects through a combination of inviting people to participate and waiting for them to ask. Villagers also recommended each other, or hinted to us that someone hoped to be invited. We regularly reviewed the characteristics of our sample, and strategised to make it deeper or more varied, often by recruiting from particular groups, especially women, or identifying specific individuals to round out the sample. During the project's four-week duration, 16 women, ranging in age from 19 to 70 , and 35 men between 18 and 75, provided us with 344 narrativised photos.

Two ways methods can deny credibility to subjects' expressive efforts is by framing research tasks too narrowly to allow meaningful self-expression (e.g., closed-ended interviews) or requiring competencies subjects don't have (e.g., standardized interviews). Accordingly, we framed our expectations as openly as possible by formulating the following simple instructions: please take pictures that convey the importance of the Shimshal Road in your everyday life, and come back to talk about them. These instructions assume the Shimshal road is important to people's lives, which imposes some constraint on subjects' self-expression. However, we had conducted enough prior research in Shimshal to be confident of villagers' sense of the road's significance. Moreover, most participants had no difficulty answering the question in both the negative and the positive, or articulating degrees of importance.

We also approached conversations with photographers as non-directively as possible. Most days we met with two to four participant-photographers. After we uploaded their photos onto our laptop (and their own USB keys to take with them), participants spent a few moments looking at them and providing brief descriptions of each, before selecting five or so photos they wanted to discuss in detail. Most photographers had 20-30 photos to select from, one elderly man had 96, and a few had less than a dozen. When participants sought our advice in selecting photos to discuss, we gently directed them toward those that expanded the variety of our data set. Observing participants select images provided a sense of what they valued in photos, especially as they often discussed the process aloud. After a participant had chosen their pictures and provided a title for each, we discussed the selected photos in detail. Conversation was moderated by the research assistants, while we took

\footnotetext{
${ }^{4}$ In 2013 Nancy and her female assistants together arranged visits to the homes of 28 middleaged and older women, to speak with them at length - over tea, and usually a meal - about their family's mobile history. These unstructured conversations in the comfort of women's homes, and in the context of their daily routines, allowed some women who may have felt uncomfortable producing photos to contribute their perspectives to the study.
} 
detailed notes, inserted our own probes, and sometimes asked for translations when the Wakhi-language discussion got too difficult. ${ }^{5}$

Most participants referred directly to their photos to address the road's importance to them. Some talked about the road but not their photos, or the photos but not the road, or neither the road nor the photos, but rather seemingly-unrelated aspects of social change in their lives. Zul Haja, for example, used a photo titled "Nazia's Umbrella" to argue that Shimshalis' identities have recently become shaped by greater integration with wider currents of thought and knowledge (Figure 2). She told us that more people are using umbrellas, sun-screen, and wide-brimmed hats to shade themselves and their children. She thinks there are two reasons for this. First, people have become more aware of the damaging health effects of solar radiation, the thinning ozone layer, etc., and are especially concerned to protect their children from the sun (note the small child on Nazia's back). Second, she speculated that as Shimshali women become more exposed to South Asian and global ideologies of youthful beauty, they are more concerned to retain a fair, unwrinkled complexion. In Ms. Haja's telling, Nazia's umbrella symbolizes a new type of Shimshali femininity: educated and preoccupied with down-country standards of beauty and motherly responsibility. As one of Shimshal's few female community leaders, and a self-styled role model for younger women, she used her photo to promote a version of femininity that she herself exemplifies. Although the road figures implicitly in Ms. Haja's reference to imported cultural influences, it serves mainly as a device for furthering her own project by way of ours. We interpret participants' moves to take control of conversations in this way as evidence that they were using the project for autoethnographic purposes.

Our plan was to meet individually with participant-photographers, accompanied by the research assistant who had recruited them, but this soon proved impractical. Most participant-photographers showed up when it was convenient for them and sat in on discussions until it was their turn, or lingered after their turn to see other photographers' pictures. Frequently half a dozen of us huddled in our room, looking at pictures, pondering their import, and drinking tea. Explanations often grew into relaxed and lively group discussions, where details were added, divergent interpretations voiced, and broader themes developed. These discussions clarified certain points of fact, but most participants presented their photos as evocations of personal experiences of mobility and change. Allowing participants to discuss their photos in a group context re-introduced certain village power dynamics into the conversational space, sometimes with negative implications for testimonial justice, as when elderly men "corrected" women's or younger people's commentaries. On the other hand, many participants would have felt more intimidated and constrained by a procedure that involved strictly-

\footnotetext{
${ }^{5}$ All Shimshalis speak Wakhi as their first language, but they are educated in Urdu and English. A few people chose to converse in English; most used Wakhi.
} 
scheduled appointments and more formal one-on-one conversations, than they were by the animated, laughter-filled, group discussions that characterized the conversational aspect of the project. Moreover, observing group discussions helped us appreciate photography as a social practice and resource for asserting identities, serving interests, and producing and negotiating truths.

The conversations generated by this procedure were remarkably rich, in terms of the range, detail and intimacy of themes, examples, and reflections participants developed. The presence of a photograph to focus attention, orient embodied presence, and mediate conversation helped dispel nervousness and awkwardness, and nurtured a relaxed atmosphere. People told us they were excited by the chance to discuss their pictures and hear others' opinions, an enthusiasm we attribute to participants' sense of discretion in terms of what photos they produced and how they were interpreted. We nurtured this discretion by involving the community and our local research assistants in design and recruitment decisions, encouraging assistants to lead discussions and manage project logistics according to local sensibilities, providing photographers with relatively open instructions, and allowing discussions to unfold as unstructured conversations among peers.

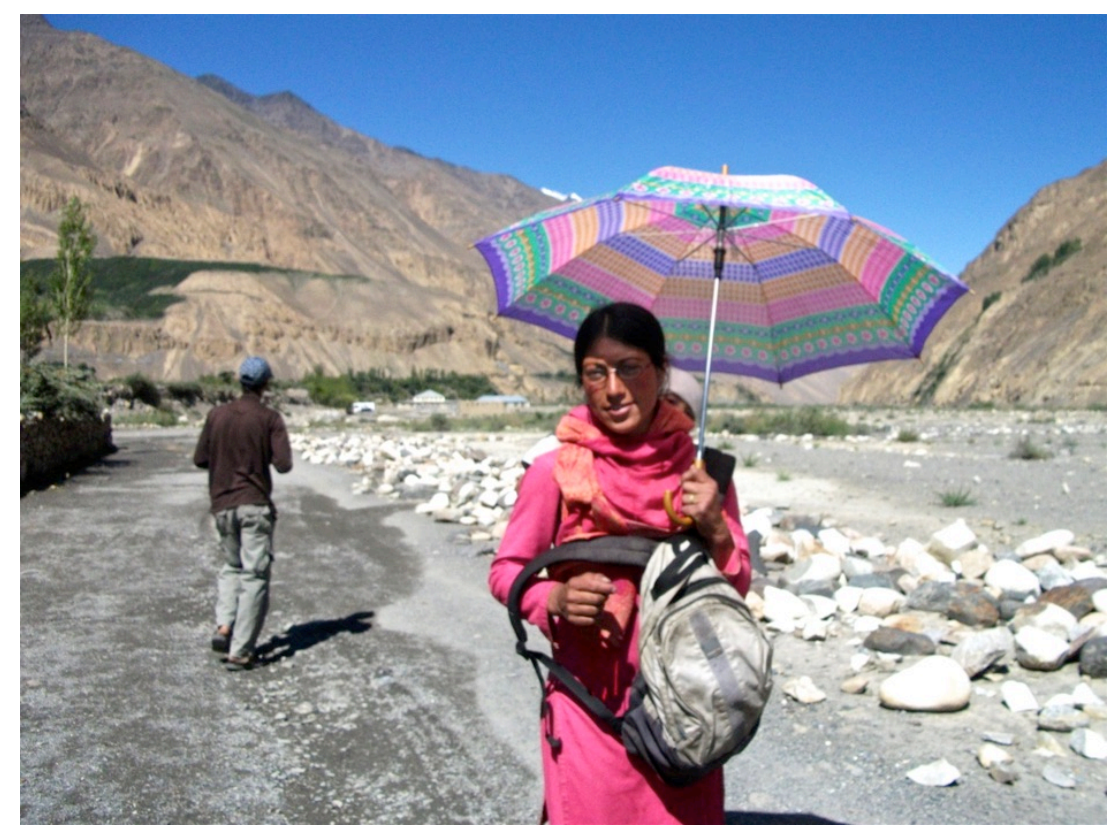

Figure 2. Nazia's umbrella (Photo: Zul Haja, 35, f, homemaker/local council member)

We also think our relatively non-directive use of autophotography has benefits in terms of hermeneutical justice: subjects' capacity to express 
themselves as they wish and to be understood on their own terms. Our openended instructions, subjects' liberty to compose photos without intervention or surveillance, and the discretion to comment on them as they pleased all contribute to this prospect. But hermeneutical justice also involves attributing credibility to subjects commensurate with the epistemological characteristics of their representations. A key epistemological feature of Shimshalis' communications with us is their autoethnographic character, and therefore our responsibility in terms of hermeneutical justice is to conduct research that nurtures an autoethnographic mode of communication, and to receive Shimshalis' self-representations with sensitivity to their autoethnographic characteristics.

If autoethnography is a form of interventionary and self-interested transcultural self-representation, which produces a reality for the self and an other, then autophotography's combination of photography and unstructured conversations has several strengths as a vehicle for autoethnographic representation. Cameras are technological extensions of a photographer's eye, which enable photographers to present viewers with a version of what they see from the same vantage point. But not exactly the same vantage point, because photographers look out toward the edge of a location centred on their own kinaesthetically-embodied presence, while viewers are situated at a scene's periphery looking into it. Photography thus both invites viewers into a scene and keeps them at bay. Shimshalis' photos offer representations of aspects of their socio-material context, but in a form mediated by this inviting/distancing characteristic of photography, as well as by the compositional discretion of photographers in terms of content (e.g., choice of scene, framing, distance) and form (e.g., exposure, depth of field, focal length) decisions, both of which are productive resources for the performance of identity. Content decisions associate the photographer-self with a social, locational, material context, and in our case present a particular rendering of their preoccupations regarding the road. Through these devices photographers may perform themselves or their community in various ways: as modern, traditional, wealthy, family-oriented, entrepreneurial, devout, thoughtful, educated, rustic, footloose, etc. Decisions related to form or aesthetics perform the self in similar ways, but in a somewhat different register, for example, as artistic, imaginative, whimsical, eager to please, rushed for time, or technically proficient.

A photo produced by a middle-aged woman from a wealthy family - Zaib Aman - illustrates autophotography's autoethnographic character (Figure 3). In her telling, this "Modern Washroom" is a space where her family experiences the effects of vehicular mobility. She said the road makes transporting bathroom fixtures possible, but only for wealthy people. She emphasised that just a few households have modern bathrooms, but everyone in Shimshal has become more concerned about cleanliness, and everyone wants these bathrooms, even if they only work half the year when the water runs. Through this combination of photo and narrative, Ms. Aman constructs 
herself as modern, wealthy, and well-educated - a trend setter - in keeping with her family's social position. The photo's contents and accompanying narrative perform her identity as distinct from other Shimshalis, while also performing the community as aspiring to the hygienic modernity she depicts. The photo is a complex, multi-scalar self-performance, in which content combines with a highly-symmetrical composition to situate her in relation to Shimshal, and Shimshal in relation to modernity.

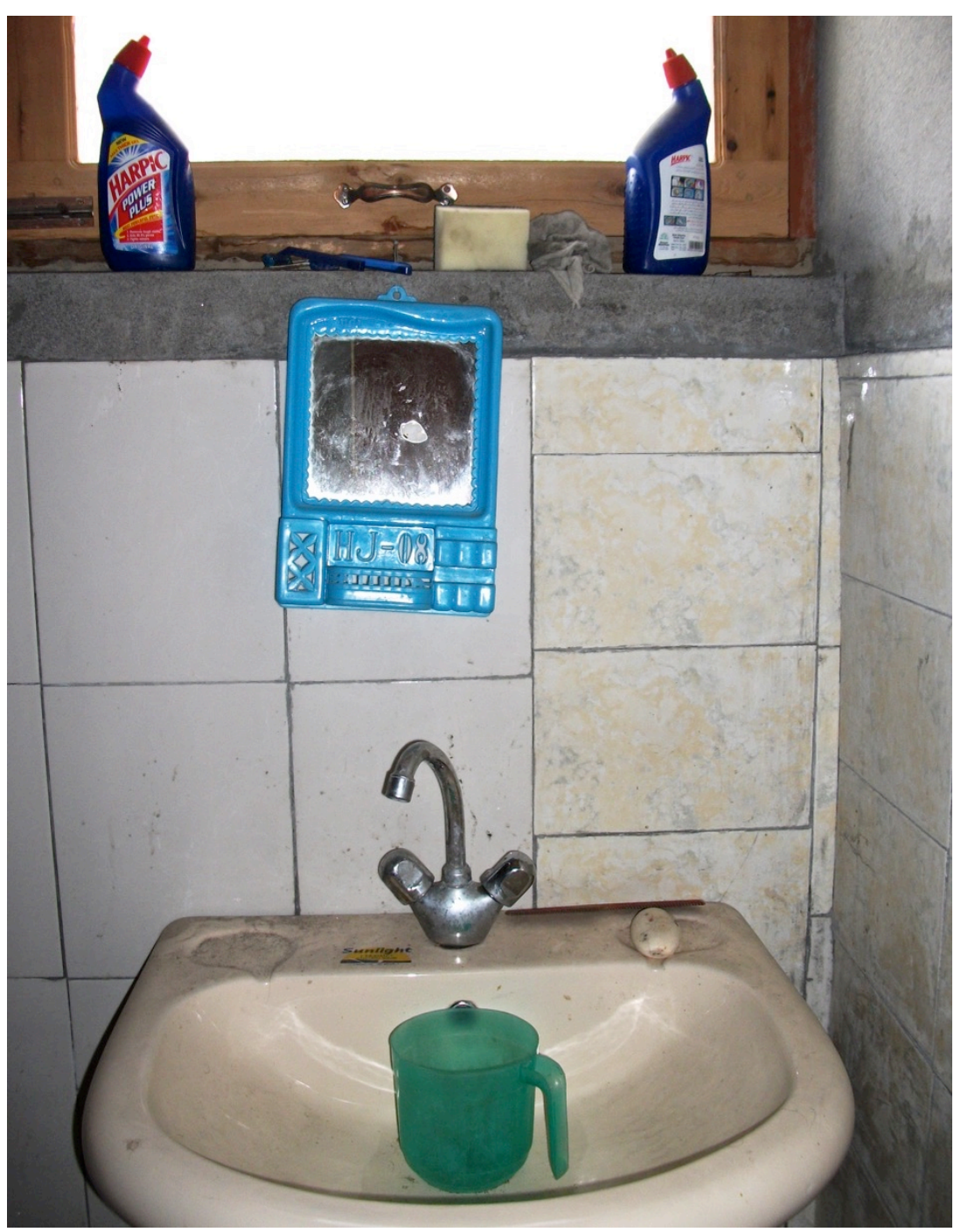

Figure 3. Modern washroom (Photo: Zaib Aman, 48, f, homemaker) 
The decisions photographers make about form and content are shaped by an anticipated context of reception: photographs are identity performances for an audience, which in our project includes photographers themselves, foreign researchers, other community members, and potentially an audience of nonShimshalis. The photographs are performances of and for an individual and ethnographic self, as well as for metropolitan outsiders, the most proximate of which - ourselves - know the community well and are understood locally as powerful producers of knowledge and valuable resources for individual and collective projects. Reading photographs as autoethnographic offers a way to practice an anti-objectivist epistemology of vision commensurate with our research context.

Autoethnographic expression has interventionary objectives, but is only successfully interventionary if it is intelligible to its metropolitan and local audiences. According to Pratt (1992), this necessitates adopting aspects of a metropolitan idiom, and mingling them with a local idiom. In Shimshal, photography exemplifies these characteristics. As an expressive practice photography is new to Shimshal, but all villagers are familiar with metropolitan photographic conventions, because they have seen countless pictures in books, magazines and increasingly on-line, including pictures of their own landscapes and social contexts in adventure tourism publications and development reports. Arguably, all of our participants were competent transcultural communicators in a photographic idiom, whether or not they were experienced photographers, because of their familiarity with metropolitan compositional conventions. Moreover, most cameras - including the Nikon Coolpix digital cameras we used - bias photographers toward producing horizontal images, impose constraints on composition (e.g., in terms of dimensions), and have automatic features (e.g., exposure, focus, depth of field), which unless overridden direct photographers to take pictures that conform to standard conventions. Cameras therefore limit photographers' creative discretion, while also providing templates for achieving a degree of transcultural intelligibility. These camera-effects undermine claims that autophotography affords autochthonous self-expression, but highlight the method's strength for generating representations that communicate across knowledge communities and thus intervene in metropolitan knowledge.

Familiarity with global compositional conventions, combined with the built-in constraints of cameras, helped photographers produce pictures that both other Shimshalis and we as researchers found sufficiently intelligible to serve as productive starting points for conversations. These conversations allowed participants to add specific and abstract meaning to their photos, with the effect of producing a richer autoethnographic intervention situated more explicitly in expressive intention and transcultural identity performance. The social situation in which photos were discussed compelled photographers to perform in the moment the autoethnographic characteristic of speaking simultaneously to an audience of insiders and outsiders. Observing photographers address multiple audiences simultaneously offered insights 
regarding photography's constitution and performance as a social practice. For example, adult participants often used the discussions to educate our young research assistants about aspects of Shimshal's past or present, thereby satisfying an intra-community didactic interest and asserting their social seniority. When these lessons contained implicit criticism of today's Shimshali youth, they were usually directed to us rather than our assistants, to avoid embarrassing them. In other cases photographers communicated points to us, ostensibly by addressing research assistants or other onlookers. Idiom and sometimes language itself - varied depending on who was being directly addressed. Many participants knew us before the project began, and almost all assumed we are familiar with community affairs, the road-building process, and life before the road; this assumption made it easier to address multiple audiences simultaneously, and to take pictures they thought would be intelligible to us. Sometimes participants used photos to continue conversations they had begun with us in other circumstances. These observations demonstrate that accuracy and authenticity are inappropriate epistemological descriptors for what our participants showed and told us, and also that the prospect of empowering participants by removing the influence of our agency and positionality from their autophotographic performances is unrealistic.

So far we have discussed two of autophotography's three main epistemological characteristics: its anti-objectivist epistemology of vision, and its participant-oriented process for generating visual-narrative data. It remains to discuss the method's reliance on portable photographic technology, which can be used in a variety of social and locational circumstances. The mobility of small cameras augments the benefits of autophotography's anti-objectivist epistemology and participant-orientation, in two respects. First, the near-global ubiquity of cameras and their easy user interface give the method considerable social mobility, enabling almost anyone with sight to create complex and deliberative images. Second, compact cameras' portability allows photos to be taken in places, at times, and of artefacts and activities embedded in subjects' daily lives that would not otherwise be accessible to researchers. Expanded possibilities for generating visual information from beyond researchers' physical and social reach helps reverse the conventional ocular gaze of research, thereby enhancing subjects' representational and interpretive discretion. The spectator's view from the edge of things, which is typically most available to researchers, is replaced in autophotography by a more intimate view. This optical and cognitive reorientation deepens the method's potential to generate rich, novel, and placeembedded insights regarding subjects' relationships to an object of inquiry.

Participants' capacity to move through their daily routines with cameras gives autophotography limited but important characteristics of a mobile method. Still cameras are not well-suited to capturing movement itself, except to the extent that photographs freeze postures or attitudes of motion. However, photos can effectively portray contexts, artefacts and consequences 
of mobility; articulations of movement itself may be added when photographers discuss their pictures. For example, an elderly man named Barkat Ali Shah produced a photo of several "Generations of Lighting," which he carefully positioned in his home (Figure 4). The photo is static almost a still life - but it became animated through Mr. Shah's explanation, which associated each type of lighting (grease lamp, coal oil lantern, hurricane lamp, high pressure propane lamp, lightbulb) with a different period in Shimshal's history of mobility. He included detailed descriptions of himself and his father carrying lamps and other unwieldy items to Shimshal by foot, and emphasised the transportation possibilities afforded by improved paths culminating with the jeep road. Evidently, he wanted to describe his family as lighting innovators in Shimshal, while also reminding research assistants of the mobility difficulties their ancestors faced. He enrolled us as allies in this didactic and self-representational effort, because unlike our assistants we had walked the route to Shimshal many times before the road's completion, and remember when currently-obsolete forms of lighting were common. Mr. Shah taught us nothing new about Shimshal's history of lighting or mobility, but the association he constructed between lighting and mobility infrastructure, and the way he wove his family's achievements into that association, alerted us to certain connections Shimshalis draw between mobility and identity, and to one of the many corners of their lives in which they discern the road's influence. That he constructed a small temporary museum of lighting specifically to photograph again demonstrates that photos produce rather than capture or mirror visual realities.

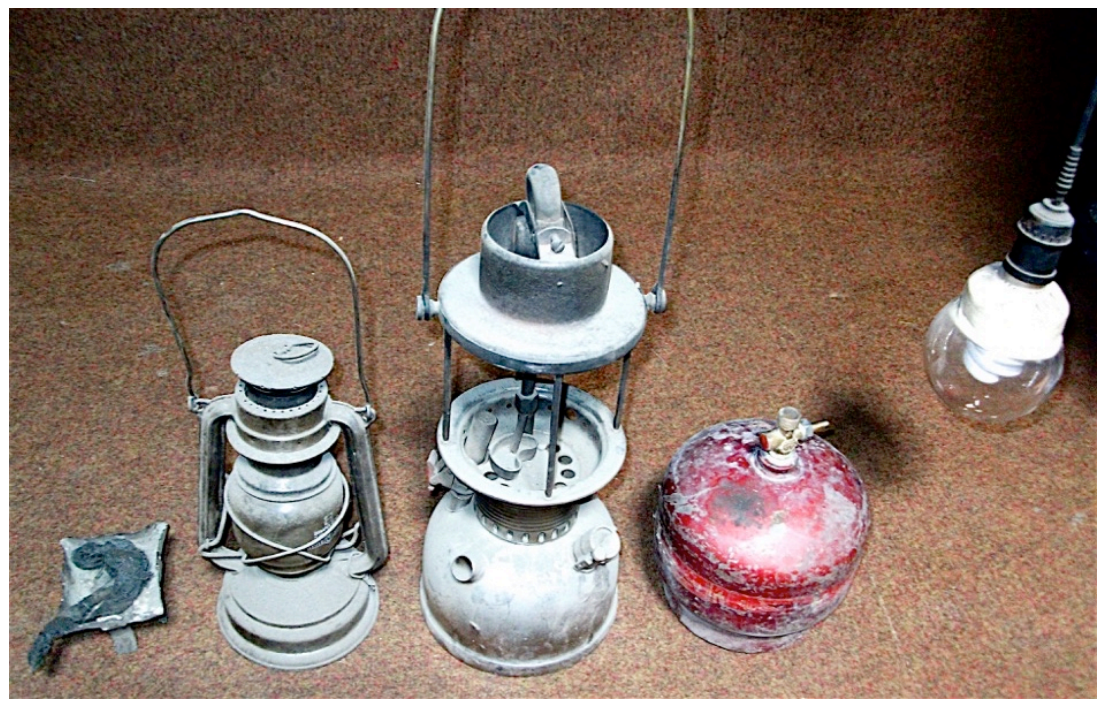

Figure 4. History of lighting (Photo: Barkat Ali Shah, 59, m, farmer/animal health specialist) 
For our purpose, which is to investigate the difference a particular mobility infrastructure is making to Shimshali lifeworlds, the capacity of photos to situate subjects' perspectives on the landscape, in material artefacts, in the spaces of their lives, is a significant benefit. Discussions of mobile methods emphasise the importance of considering mobility in relation to materiality, embodiment and place (Cresswell, 2006, Merriman, 2014, Spinney, 2015). Hein, Evens and Jones (2008, p. 1269; emphasis in original) stress that "materiality is the simple acceptance that people, things, and even ideas are situated somewhere," and note that "the idea of embodiment is closely related to place, which recognises that the position of a phenomenon in space and time is an essential determinant of its characteristics" and, we would add, of the characteristics of the place in which it is positioned. These insights have three implications for our research, which relate to our use of autophotography.

First, if we are interested in how new mobility infrastructure intersects with people's lives, it is insufficient to focus on the experience, practice and representation of movement through a landscape or in places; we should also study how the socio-material character of places are reshaped by the infrastructure and the mobilities it affords. This is especially important in Shimshal, where the embodied mobilities of much of the population have not been noticeably affected by the road's construction (see Cook \& Butz, 2017), but whose lives have been reshaped by a new landscape of artefacts transported along the road. The road's "meaning" to many Shimshalis has less to do with greater ease of personal travel than with changes to their homes or re-landscaping of the village. Participants exploited the portability of cameras to photograph a range of village places they wished to represent as materially reconstituted by artefacts that were uncommon or unavailable in the village before the road's construction. They framed, composed and visually "froze" these artefacts, either in situ or in an arrangement tailor-made to photograph. Photos portrayed the material aspects of these socio-material changes to place, while the social implications of changing materiality were often addressed in photographers' commentaries.

Naveed Ahmed, for example, photographed an assortment of new electric kitchen appliances located in a relative's traditional kitchen (Figure 5). The picture portrays the material make-up of a household space, and hints at aspects of women's reproductive labour. His commentary reflected on household economies and changes in the way husbands and wives relate. He stated that the man in this household works many hours for low wages in a distant city to purchase and transport consumer items that save his wife a small amount of labour. In Mr. Ahmed's telling, these appliances are not very useful in Shimshal, except to signify the man's appreciation for his wife's efforts to maintain a home in his absence, and as a materially-emplaced symbol of his purchasing power. It is hard to imagine either this intense focus on a micro-environment, or Mr. Ahmed's sophisticated commentary, arising from a go-along visual-mobile method, or from a more conventional 
interview process in which selectivity and premeditation are more difficult. Mr. Ahmed, a young student eager to perform himself as studious, treated the exercise as a research assignment, carefully selecting his scene, composing his picture, and speaking with the homemaker, before offering commentary. ${ }^{6}$

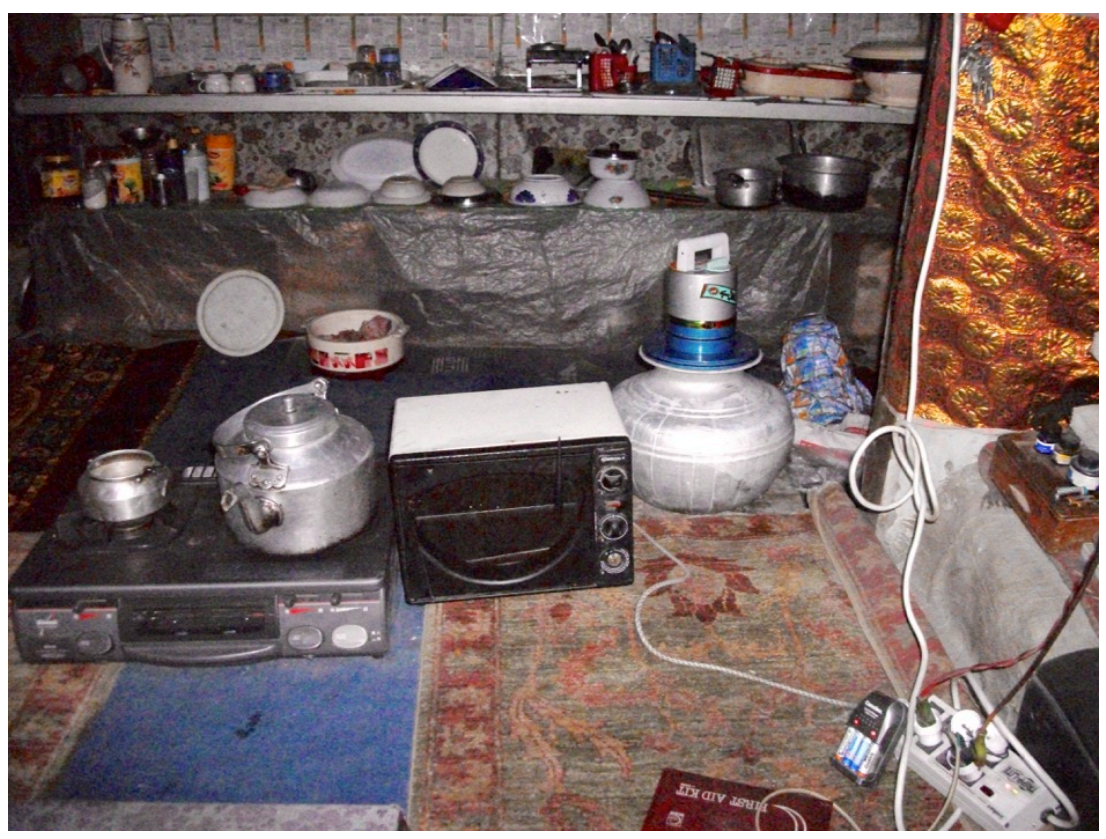

Figure 5. Old kitchen with modern equipment (Photo: Naveed Ahmed, 18, m, student)

Autophotography's capacity for fine-grained selectiveness also has benefits for epistemic justice relative to move-along visually- or kinaestheticallyoriented methods. The latter may allow subjects to select a route, but not to limit the accompanying researcher's apprehension of scenes or events along it. Mr. Ahmed could have taken us to this house, showed us the appliances, and talked about them in situ; but he couldn't do that without exposing us to other parts of the house, other artefacts in the house, or household members, any of which may have interfered with his argument. Moreover, he may have felt compelled to answer our questions about things we saw during our outing together or think on his feet in ways that prevented him from shaping his intervention as he wished.

Second, to say that "the position of a phenomenon in space and time is an essential determinant of its characteristics" (Hein, Evens \& Jones, 2008, p.

\footnotetext{
${ }^{6}$ An objectivist reading of the photo would produce a different interpretation than the photographer wished to promote.
} 
1269) suggests that place is an actant in the research process: where people are located influences what seems important or true to them, and their performances of self. The road's meaning to Shimshalis may vary depending on where they are; their preoccupations in relation to it are place specific. Mobile methods such as walking interviews address this issue by allowing researchers to move through a landscape with participants, but with the disadvantages specified above, and usually with significant spatial limitations (Warren, 2017). Autophotography allows subjects to place themselves in various locations, make photos that relate to their thoughts in those places, and use those photos to inform subsequent discussion in a different place. This process does not remove the influence of the socio-spatial context in which subjects discuss their photos (i.e., our room, in the company of our assistants and assorted onlookers); nor would we want it to, given the autoethnographic resources to be found there. But it does allow photographers to bring self-performances that are constituted in the places of their daily lives into the interview context in the form of photographs. Again, we aren't implying that this gives us a more accurate rendering of who people are, what they think, or how the road is important to them, but it does expand the range of embodied locations from which they perform and communicate for us. The extent of this expansion depends on the spatial range and variety of photographers' daily routines, and on the duration they have to produce photos.

To make the best use of our cameras in a limited field season, and to prevent them being lost or damaged, we allowed participants to keep them for one day only. This short duration limited the range and variety of locations subjects could photograph, especially for female homemakers whose reproductive labour kept them busy and close to home. They mainly photographed the interiors of their houses, their children, or outside spaces close to home. Among our female participants, only young students, grandmothers and those with leadership positions in community organisations photographed spaces distant from their homes. Men took pictures in and of a wider variety of domestic and public spaces, commensurate with their greater and more autonomous mobility. Men were also more likely to include wideangle landscape shots, while women usually focused more tightly on things close to them. The photographs as a set provide some indication of differences in daily mobilities between and within genders, but not straightforwardly, because homemakers used their photos to perform homemaker identities, female students performed identities as modern and emancipated by photographing shops and other public spaces, and men performed authoritative masculinity via a wide range of interior and exterior shots, including prospects from vantage points above the village. The photos reproduce - or challenge - gendered expectations as much as they represent gendered patterns of mobility.

Two pictures produced by the late Mohammad Shafa exemplify how the road's meaning may vary depending on where photographers are. The first is 
of an old hand-woven yak hair carpet in Mr. Shafa's home (Figure 6). His commentary stressed the beauty, durability, and significance of village-made carpets, before reflecting on the loss of these aspects of local culture as the road brings cheaper and gaudier manufactured replacements. The conversation was saturated with the regret and nostalgia of a widower whose only child lives far away, for whom home is a lonely reminder of a happier past. The second photo shows the Shimshal cricket team returning triumphantly from a tournament in another village (Figure 7). Here $\mathrm{Mr}$. Shafa's commentary focused on Shimshal's history of sporting excellence and the new opportunities village athletes have to distinguish themselves now that the road makes travel to tournaments easy. The two photos - one a closeup interior in a lonely home, the other a wide-angle shot of a happy moment in village life - generated quite different takes on the road, the village's future, and Mr. Shafa himself.

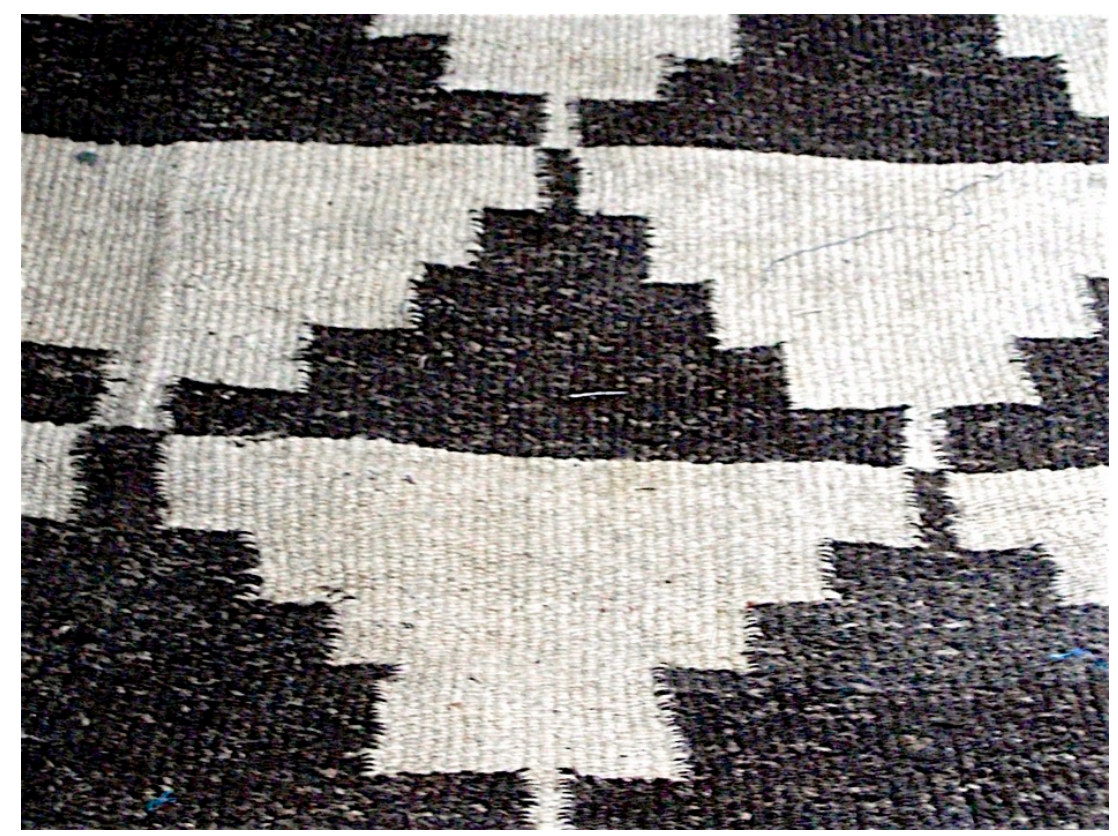

Figure 6. Qolen plos (a specific pattern of yak hair carpet) (Photo: Mohammad Shafa, 63, m, farmer) 


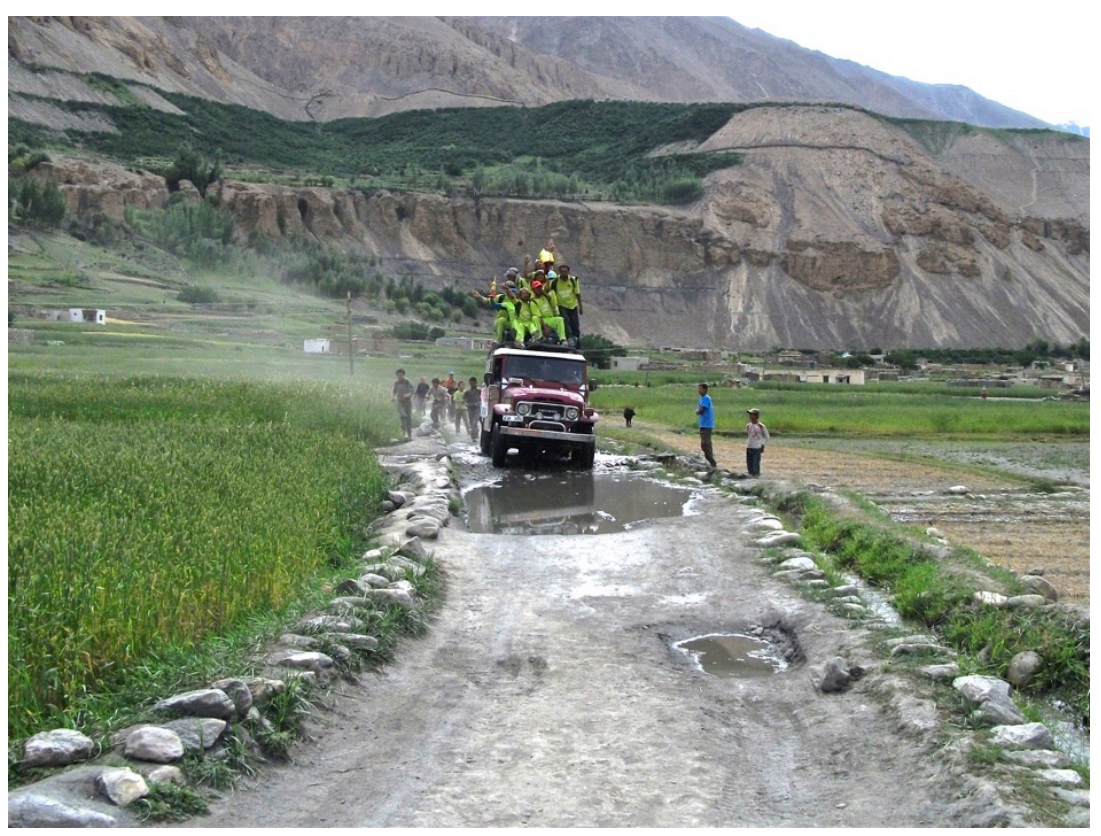

Figure 7. The cricket team arrives (Photo: Mohammad Shafa, 63, m, farmer)

A third important reason to situate Shimshalis' perspectives in the spaces of their lives via autophotography is to distance our analysis from the global North-centrism of mobilities research. Although "road impact" studies are common in international development scholarship, few studies employing a mobilities perspective have focused on South and Central Asian mobility articulations (but see Butz \& Cook, 2011, 2015; Hussain \& Smith, 1999; Shneiderman, 2013; Sur, 2013). Consequently, theorisations of mobility risk presuming a normative infrastructural environment characteristic of the industrialised North, with commensurate assumed artefacts, practices, subjectivities and mobility inequalities. A well-developed transportation infrastructure is assumed in most of the conceptual literature, as are a variety of motorised conveyances or at least wheeled vehicles. Even studies of walking situate pedestrian movement in an environment of machines, as an alternative or complement to vehicular mobility. Mobile subjects are imagined to be competent passengers, if not always drivers. These underlying assumptions don't hold for much of the global South. Among Shimshal's adult population some individuals have never ridden a wheeled vehicle, and for many people traveling by jeep is still a rare experience. Women often display a visceral dread of jeep travel, and their frequent "car-sickness" is received as a positive display of Shimshali femininity. Artefacts that are too large, heavy or fragile to be carried by foot still stand out as new in a built landscape that was until recently shaped solely by the affordances and 
limitations of pedestrian movement. How to produce an analysis that benefits from the many conceptual insights of mobilities scholarship without assuming the same ontological ground that underpins that scholarship, and how to articulate the features of Shimshal's mobility context in relation to mobilities research without sensationalizing, othering, or locating it in the past are challenging questions. A full answer is beyond this paper's scope, but must involve attention to Shimshalis' own attentiveness to the subtle implications of place for the experience of a new vehicular mobility platform, and of vehicular mobilities for the micro-constitution of place. Autophotography is a useful resource for developing such attentiveness.

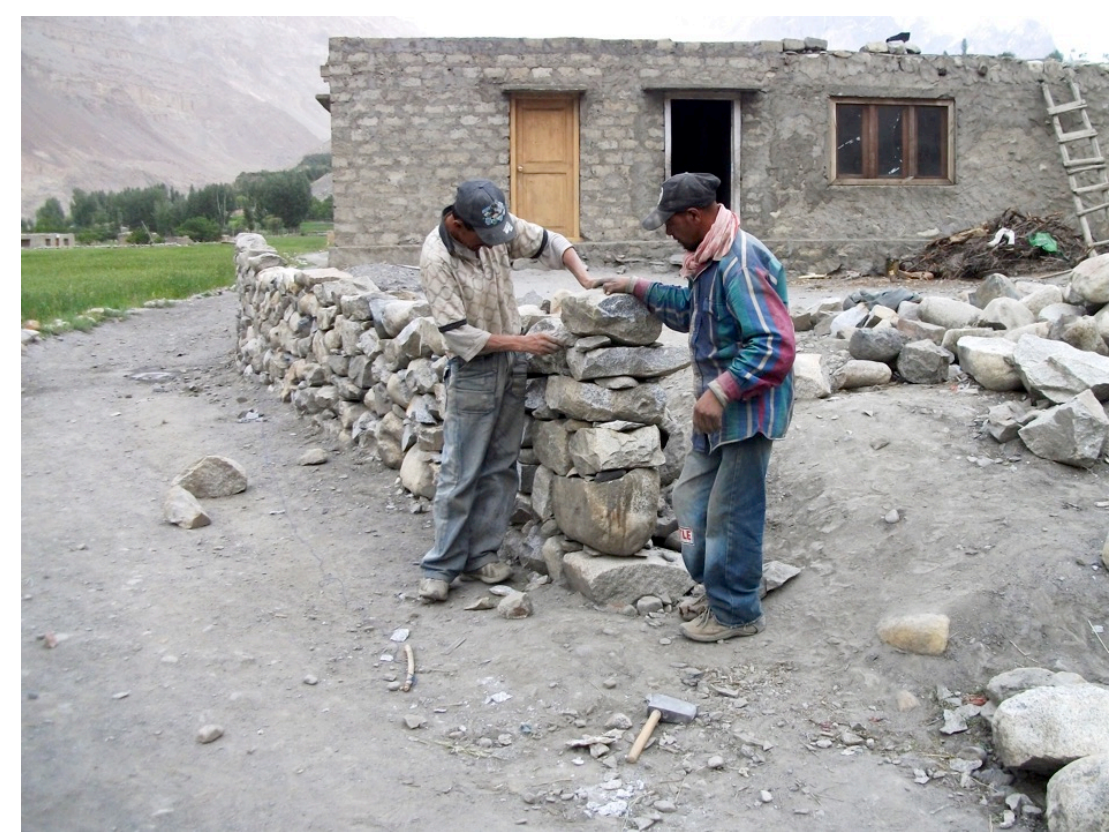

Figure 8. Privacy wall (Photo: Naveed Ahmed, 18, m, student)

A second photo by Naveed Ahmed helps to illustrate autophotography's utility in this regard (Figure 8). It shows two men building a boundary wall to separate the roadway from private property. In Mr. Ahmed's telling, the road passes close to people's homes, which disrupts their privacy and security, and endangers children. Recently, such walls have become common in Shimshal, to protect crops from livestock, and to satisfy a growing desire for personal privacy. According to Mr. Ahmed, the new roadway is understood as public space, where anyone can walk freely, socialise, or conduct business. Other village spaces, including paths between fields and along irrigation channels, have become less public, a circumstance reinforced by boundary walls. Consequently, villagers feel less free to use these paths than formerly, and 
landowners are increasingly likely to prevent other villagers from crossing their property. Mr. Ahmed said that villagers now use the main road to walk from place to place, even if their journey takes longer. He concluded that although the road enables long distance vehicular mobility, it decreases the efficiency of pedestrian movement within the village. His commentary begins with the emplaced, embodied action portrayed in the picture. He then widens his scope, using boundary wall construction as a resource to talk about the road's disruptive implications in Shimshal, with its particular history of mobility: impeding pedestrian movement, strengthenening the differences between public and private space, endangering children and livestock, and changing sight-lines. Whatever we make of this combination of photo and narrative in terms of accuracy or performativity, it articulates an attentiveness to place that pries us loose from the metropolitan imaginaries of much mobilities research, which casts roads as mundane, boring, even passé. Through its intense place-specificity, Naveed Ahmed's production intervenes in these imaginaries.

This paper responds to calls from mobilities scholars for methodological innovation and reflexivity by detailing our use of autophotography and assessing its characteristics as a visual/narrative method for mobilities research. Taking inspiration from Fricker's (2007) conceptualisation of epistemic justice, we start from the position that ethics and epistemology are mutually constitutive, and therefore that methods must be assessed situationally on ethical and epistemological grounds. Pratt's (1992) concept of subaltern autoethnography provides a productive epistemological framing for transcultural research interactions in our colonially-inflected context, from which we develop a set of epistemological/ethical research priorities that together constitute an autoethnographic sensibility; for autophotography to be suitable for our research it should allow subjects relatively unrestricted opportunities for autoethnographic expression, and constitute data in a form that is amenable to interpretation and analysis as autoethnographic. We argue that autophotography's combination of visual/narrative self-expression meets these criteria, if two temptations are avoided: to imagine visuality as a shortcut to accuracy or authenticity; and to imagine the participatory character of autophotography as empowering to research subjects. Conceiving of autophotography's yield as autoethnographic helps avoid these temptations.

Meeting the ethical and epistemological requirements of an autoethnographic sensibility is a necessary but insufficient criterion for claiming a method is suitable for mobilities research. It must also have the capacity to generate insights regarding the activities, events and meanings through which mobilities are socially instantiated. Numerous mobilities scholars have argued that this requires explicitly mobile methods that involve researchers moving with or visually tracking mobile subjects in motion. 
Although we appreciate the advantages of mobile methods for certain mobilities research, in some settings they may impede epistemic justice by excluding certain groups from participating, and by constraining autoethnographic expression among individuals who do, with detrimental epistemological effects. Autophotography's process of inviting subjects to take photos at times and places of their choosing and then discuss their significance at a later time in another place can attenuate these liabilities, while retaining many of the strengths of go-along methods. Similar to more explicitly mobile methods, autophotography situates subjects' perspectives in the socio-material spaces of their lives, allowing them visually to perform the material contexts, artefacts and consequences of mobility, and to later add verbal articulations of movement itself.

Autophotography's capacity to produce visual representations that are emplaced in the spaces of subjects' daily lives is a significant advantage for mobilities research, especially in contexts where changes to the material and social character of place are experienced as important lifeworld consequences of a new mobility constellation. Specifically, this capacity helped us investigate how the socio-material character of Shimshali places are reshaped by the new road and the movement it affords, and how the places in which Shimshalis contemplate the road's significance influence their perspectives and the ways they are articulated. Moreover, autophotography's microattention to place and people's embodied occupation of specific places helps us consider features of Shimshal's mobility context in relation to a larger ouvre of mobilities scholarship, while remaining sensitive to ontological differences between Shimshal and the global North settings that much mobilities scholarship investigates and presumes. Although we articulate these advantages in relation to our own research context, we don't think they are limited to it.

We have insisted that for epistemological and ethical reasons Shimshalis' pictures and commentaries should be understood as autoethnographic: reflexive self-performances that produce rather than reflect a version of truth. Although we asked Shimshalis to take pictures that convey the importance of the Shimshal Road in their everyday life and then tell us about them, we cannot analyse the resulting representations as capturing or accessing realities about the road's significance that pre-exist their visual/narrative expression to us. ${ }^{7}$ Instead, we must read the photos and narratives as transcultural performances of identity in relation to the road, which have been shaped by the affordances and constraints of autophotography, and by characteristics of the field of power in which it was employed. Similarities among participants in terms of the content or form of visual/narrative productions demonstrate

\footnotetext{
${ }^{7}$ Photos demonstrate the existence in Shimshal of certain artefacts like sinks, lamps, kitchen appliances and boundary walls, and in their commentaries photographers provided factual information about the cost of travel, the number of tractors in the village, their own mobility patterns, etc. Some of these factual details are helpful to our investigation, but they are byproducts of autophotography that hardly justify the method.
} 
that individual photographers are using the road discursively as an identityperforming resource in shared ways. Consequently, one relevant analytical question is, how are Shimshalis using the road as a discursive resource for the constitution of individual and collective identity? (see Campbell, 2012; Dalakoglou \& Harvey, 2012; Demenge, 2012). Although a detailed answer is not possible here, we devote our final paragraphs to illustrating how pictorial and narrative references to the road were used to promote three overlapping discourses of Shimshali identity.

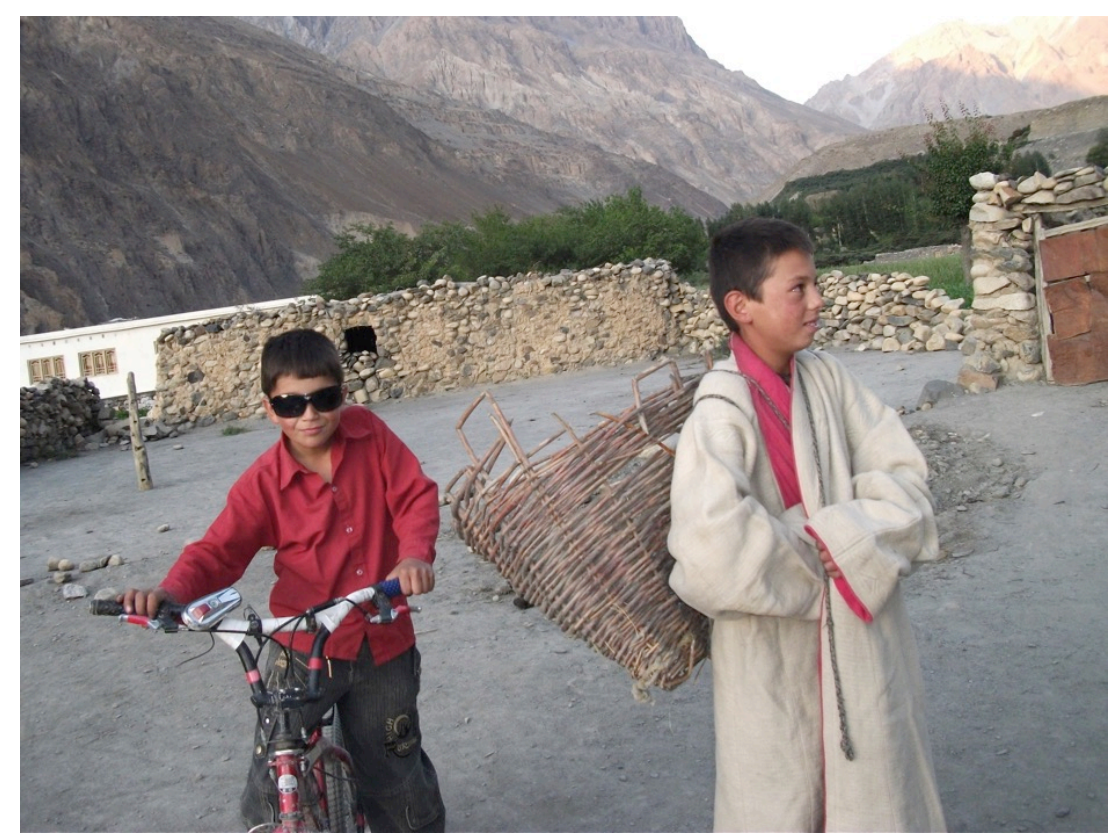

Figure 9. Old and new boy (Photo: Sher Ali, 50, m, teacher)

First, a majority of participants referenced the road or road-based mobility as a device for situating Shimshal in relation to modernity and tradition. The road's construction was portrayed as a pivotal event, separating past from present, tradition from modernity. In these tellings the road was itself evidence of modernity and the propellant for other changes that brought modernity and eroded tradition. Participants had various takes on the attractiveness of modernity in relation to tradition, but almost everyone stressed their own and the community's status as modern. An example of this past/present interpretive framing was staged by retired teacher Sher Ali, in a picture titled "Old and New Boy" (Figure 9). On the left is a modern Shimshali boy, with his sunglasses, bicycle, clean Western clothes and cheeky grin. On the right is a so-called traditional boy from Mr. Ali's own youth, dressed in old-fashioned clothing and carrying a basket for 
transporting manure. In his commentary, Mr. Ali seemed both proud that today's youngsters enjoy free time and nice possessions, and regretful that they are an expense to their parents rather than a productive resource as he was as a boy. The main theme in his narrative was a sense of the road as a pivotal event that clearly separates the traditional past from the modern present. Mr. Ali juxtaposed tradition and modernity in a single composition; numerous other photographers presented photos in pairs to achieve the same effect.

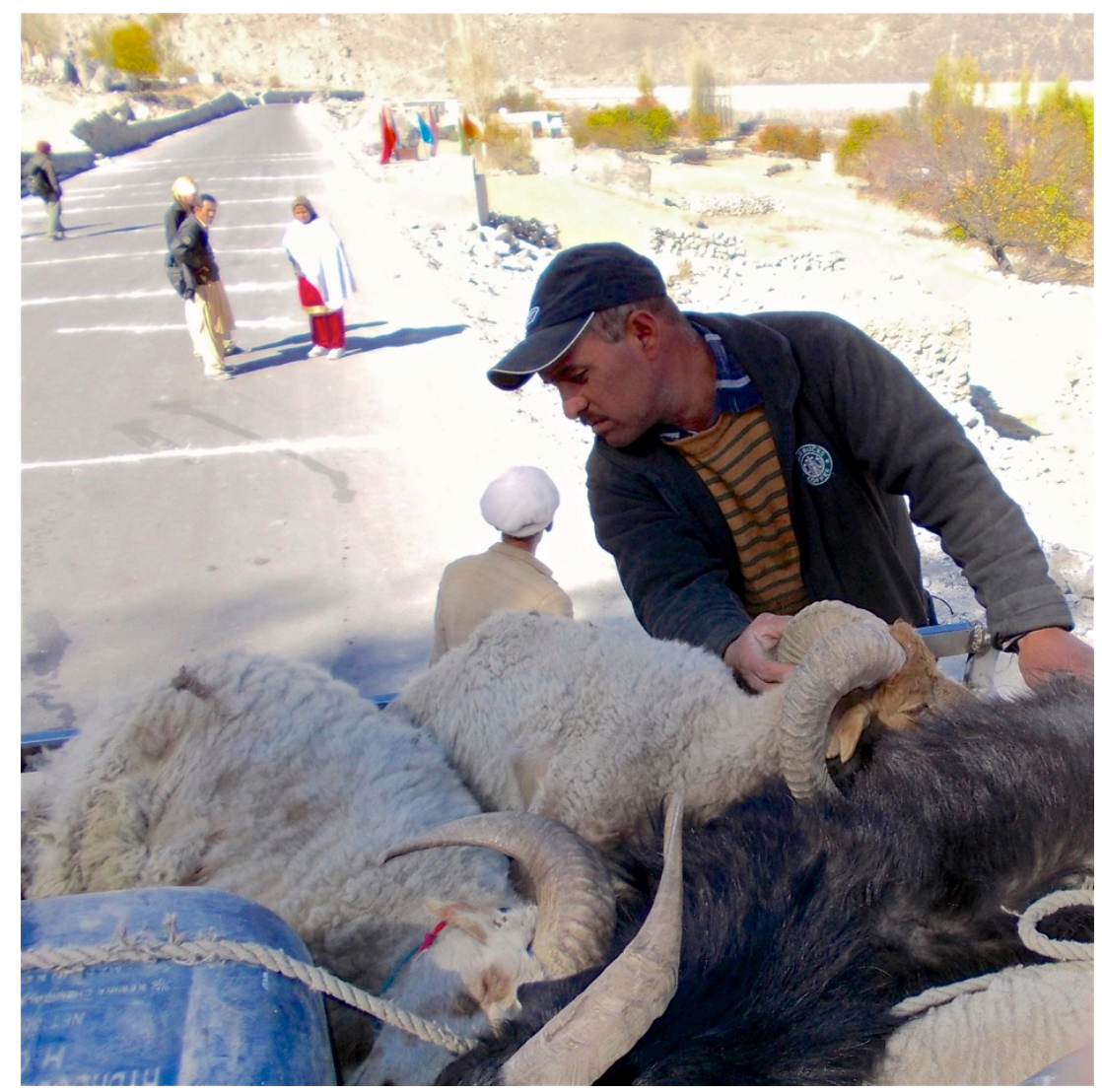

Figure 10. Wedding gift (Photo: Mirza Aman, 45, m, jeep driver)

Second, many photographers employed the road discursively to position Shimshal in relation to other places. Sometimes, as in "Boundary Wall" and "Nazia's Umbrella," the emphasis was on Shimshal's increasing similarity to larger and more urban places. In these instances the discourse of Shimshal's increasing modernity was linked to a narrative of diminishing distinctiveness, a concern that animates much Shimshali conversation. Other photographers 
incorporated the road into assertions of Shimshal's continuing cultural distinctiveness, even from neighbouring villages. Mirza Aman, one of Shimshal's passenger jeep operators, submitted a picture of himself unloading goats from the roof of his jeep, which he transported from Shimshal as gifts for a wedding in a nearby community (Figure 10). He related that weddings require numerous meat dishes, and Shimshal is famous for livestock, which can now be transported live along the road. Consequently, Shimshalis get invited to many weddings in neighbouring villages, with the expectation that they will bring sheep or goats as gifts. He complained that guests from other villages give blankets or tea sets worth 500 rupees, but Shimshalis are expected to donate an animal worth up to 15 times that amount. Embedded in Mr. Aman's mobility account are distinctions that position Shimshal positively in relation to its neighbours. The road is represented as bringing these longstanding comparative identity features to the fore in particular ways.

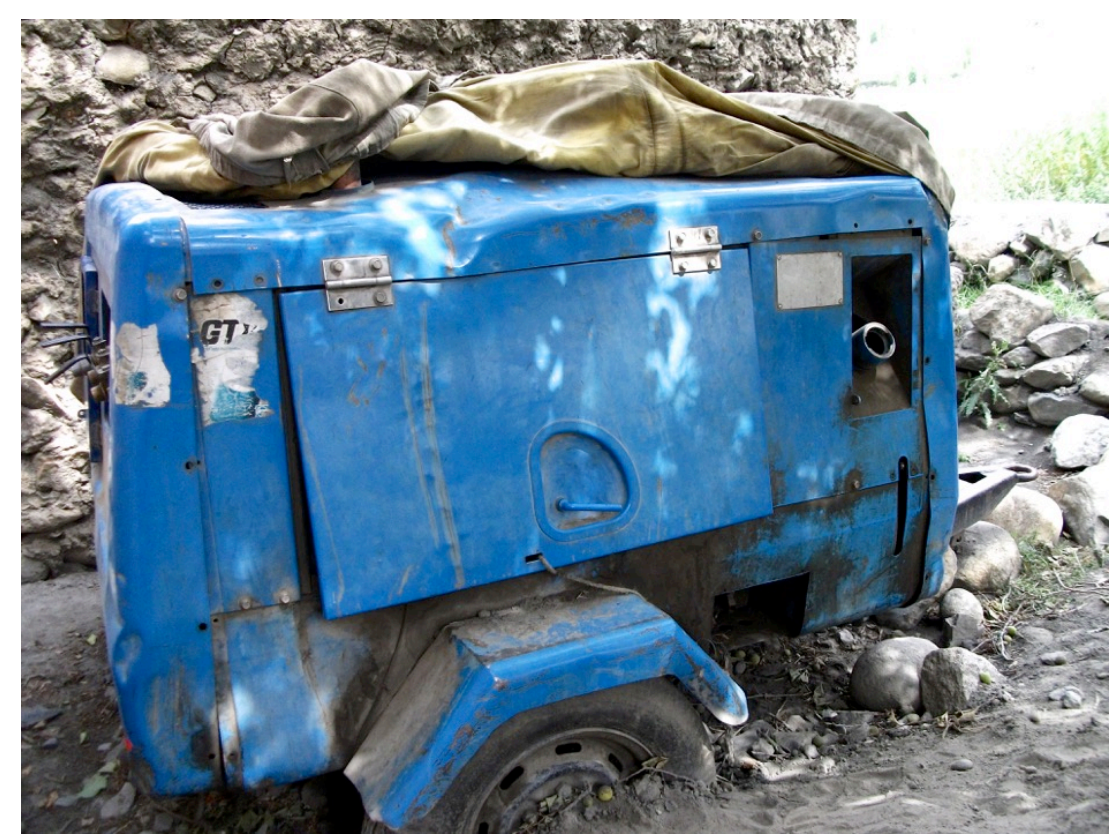

Figure 11. Compressor machine (Photo: Sifaat Karim, 32, m, electrician/shopkeeper/farmer)

Third, Shimshalis frequently produced photos and commentaries that situate villagers in relation to each other, often by drawing on the trope of village unity, specifically the ways modernisation has eroded it, and demonstrations that Shimshal remains a unified community despite modernization. Most photographers associated village unity with a traditional 
past before the road, and blamed new market relations, greater economic differentiation, and more distanciated social networks for what they represent as a decline in unity. Nevertheless, they differentiated Shimshal positively from other villages by insisting that it remained more unified than most. Numerous photographers represented the road-construction process as an important unifying event, but the road itself as an agent of dis-integration. Three photographers took similar photos of an air compressor, around which they constructed the latter claims. The compressor was donated early in the road-construction process, and used by Shimshali volunteers to drill holes for blasting. It now sits abandoned in the corner of a field. Sifaat Karim, a shopkeeper who took one of these photos, told us that to him the compressor signifies both unity and disunity (Figure 11). It is a reminder of the village's unity during the construction process, the recent erosion of which is signified by the compressor's current neglected condition. According to Mr. Karim, people have become more focused on self-interest rather than the wellbeing of the village. He attributed this change to people's greater interaction with and dependency on the outside for education, employment, and donations. As villagers rely more on distanciated cash relations and less on subsistence relations with other villagers, they have less time and incentive to help each other. Like other photographers, Mr. Karim associated different Shimshali identities with different phases in the community's relationship with the road.

As these examples indicate, Shimshalis' visual/narrative productions offer many truths about the road's importance, truths produced in a particular transcultural context, tethered to the times, places and artefacts portrayed in the photos, and shaped by individual and shared self-representational interests. ${ }^{8}$ In the process, photographers used the road as an interpretive frame to communicate something about themselves, to position their community in relation to modernity and tradition, to distinguish themselves from their neighbours, and to articulate well-worn worries about the consequences of social change. We conclude that the road's discursive usefulness is an important part of its significance to Shimshalis. This may be the most productive analytical insight we gained from our autophotography project, and the one with greatest potential to contribute to mobilities scholarship. In 2006, Tim Cresswell characterised mobility as "socially produced motion" consisting of movement, representation and practice (p. 3). Since then, the meanings that are attached to motion, mobile populations and the infrastructure that enables movement have been an important focus of

\footnotetext{
${ }^{8}$ In addition to analysing these autoethnographic productions, it is important to circulate them locally and transculturally in a form close to how they were presented to us. For that reason, and with photographers' encouragement, in 2012 we mounted an exhibition in Shimshal of 114 of the photos with accompanying captions, to coincide with the ninth anniversary of the road's completion. The printed photos remain as a permanent archive in the community. We are also producing a book that features 130 of the photos with lengthy summaries of photographers' commentaries in English, Urdu, and Wakhi. The book will be available locally, throughout Pakistan, and abroad.
} 
mobilities inquiry. Our study contributes to that focus in two ways: by creating a context for Shimshalis to articulate versions of the road's meaning to them, and more innovatively, by reversing Cresswell's formulation to show how the road is used representationally to give meaning to other aspects of themselves and their lives.

\section{Acknowledgements}

We are grateful to our Shimshali hosts, collaborators and participants for their enthusiastic involvement in our research; special thanks to the family of Daulat Amin, our long-term hosts in Shimshal, and to our excellent research assistants, Fatima Parveen, Shamshad Begum, Sakhawat Ali and Javed Shafa. Thanks also to Loris Gasparotto for his cartographic assistance. The paper has benefitted from the thoughtful suggestions of two anonymous reviewers and of special issue editors Andrea Doucet and Jennifer Rowsell, for which we are appreciative. This work was supported by the Social Sciences and Humanities Research Council (grant number 4102009 0579), and the Brock University Council for Research in the Social Sciences.

\section{References}

Aitken, S. C., \& Wingate, J. (1993). A preliminary study of the self-directed photography of middle-class, homeless, and mobility-impaired children. The Professional Geographer, 45(1), 65-72.

Allan, A. (2012). Power, participation and privilege-methodological lessons from using visual methods in research with young people. Sociological Research Online, 17(3), 8.

Alejandro Leal, P. (2007). Participation: The ascendancy of a buzzword in the neo-liberal era. Development in practice, 17(4-5), 539-548.

Anderson, E. (2012). Epistemic justice as a virtue of social institutions. Social Epistemology, 26(2), 163-173.

Bananuka, T., \& John, V. (2015). Picturing community development work in Uganda: Fostering dialogue through photovoice. Community Development Journal, 50(2), 196-212.

Belin, R. (2005). Photo-elicitation and the agricultural landscape: 'Seeing' and 'telling' about farming, community and place. Visual Studies, 20(1), 56-68.

Booth, T., \& Booth, W. (2003). In the frame: Photovoice and mothers with learning difficulties. Disability \& Society, 18(4), 431-442.

Bryne, E., Daykin, N., \& Coad, J. (2016). Participatory photography in qualitative research: A methodological review. Visual Methodologies, 4(2), 1-12.

Bukowski, K., \& Buetow, S. (2011). Making the invisible visible: A photovoice exploration of homeless women's health and lives in central Auckland. Social Science \& Medicine, 72(5), 739-746.

Büscher, M. 2006. Vision in motion. Environment \& Planning A, 38(2), 281-299.

Büscher, M., Urry. J., \& Witchger, K. (Eds.) (2010). Mobile methods. London: Routledge.

Butz, D. (2010). Autoethnography as sensibility. In D. DeLyser, S. Herbert, S. Aiken, M. Crang \& L. McDowell (Eds.), The Sage handbook of qualitative geography (pp. 138-155). London: Sage.

Butz, D., \& Besio, K. (2004). The value of autoethnography for field research in transcultural settings. The Professional Geographer 56(3), 350-360. 
Campbell, J. M. (2012). Between the material and the figural road: The incompleteness of colonial geographies in Amazonia. Mobilities, 7(4), 481-500.

Carnahan, C. R. (2006). Photovoice: Engaging children with autism and their teachers. Teaching Exceptional Children, 39(2), 44-50.

Castleden, H., Garvin, T., \& Huu-ay-aht First Nation. (2008). Modifying photovoice for community-based participatory indigenous research. Social Science \& Medicine, 66, 1393 1405.

Clark-Ibáñez, M. (2004). Framing the social world with photo-elicitation interviews. American Behavioural Scientist, 47(12), 1507-1527.

Cook, N., \& Butz, D. (2017). Gendered mobilities in the making: Moving from a pedestrian to vehicular mobility landscape in Shimshal, Pakistan. Social \& Cultural Geography. DOI: 10.1080/14649365.2017.1294702

Cook, N., \& Butz, D. (2015). The dialectical constitution of mobility and immobility: Recovering from the Attabad Landslide disaster, Gojal, Gilgit-Baltistan, Pakistan. Contemporary South Asia, 23(4), 388-408.

Cook, N., \& Butz, D. (2011) Narratives of accessibility and social change in Shimshal, northern Pakistan. Mountain Research and Development 31(1), 27-34.

Corcoran, S. (2015). Visualizing transitions: The use of auto-photography with formerly streetconnected boys in Kenya. In S. Miles \& A. Howes (Eds.), Photography in educational research: Critical reflections from diverse contexts (pp. 168-181). New York: Routledge.

Crang, M. (1997). Picturing practices: research through the tourist gaze. Progress in Human Geography, 21(3), 359-373.

Crang, M., 2010. Visual methods and methodologies. In D. DeLyser, S. Herbert, S. Aiken, M. Crang \& L. McDowell (Eds.), The Sage handbook of qualitative geography (pp. 208-224). London: Sage.

Cresswell, T. (2006). On the move: Mobility in the modern western world. London: Routledge.

D'Andrea, A., Clolfi, L., \& Gray, B. (2011). Methodological challenges and innovations in mobilities research. Mobilities, 6(2), 149-160.

Dalakoglou, D., \& Harvey, P. (2012). Roads and anthropology: Ethnographic perspectives on space, time and (im) mobility. Mobilities, 7(4), 459-465.

Delgado, M. (2015). Urban youth and photovoice: Visual ethnography in action. New York: Oxford University Press.

DeMarie, D. (2010). Successful versus unsuccessful schools through the eyes of children: The use of interviews, autophotography and picture selection. Early Childhood Research \& Practice, 12(2), 1-17.

Demenge, J. P. (2013). The road to Lingshed: Manufactured isolation and experienced mobility in Ladakh. HIMALAYA, the Journal of the Association for Nepal and Himalayan Studies, 32(1), article14.

Dixon, M., \& Hadjialexiou, M. (2005). Photovoice: Promising practice in engaging young people who are homeless. Youth Studies Australia, 24(2), 52-56.

Faber, S. T., Møller, K. T., \& Pristed Nielsen, H. (2013). Applying visual methods in the study of place affiliation, mobility, and belonging. Graduate Journal of Social Science, 10(2), 43-53.

Fincham, B., McGuiness, M., \& Murray, L. (Eds.) (2010). Mobile methodologies. New York: Palgrave Macmillan.

Ford, K., Bray, L., Water, T., Dickinson, A., Arnott, J., \& Carter, B. (2017). Auto-driven photo elicitation interviews in research with children: Ethical and practical considerations. Comprehensive Child \& Adolescent Nursing, 40(2), 111-125.

Fricker, M. (2007). Epistemic injustice: Power and the ethics of knowing. New York: Oxford University Press.

Gilman, S. (1986). Black bodies, white bodies: Toward an iconography of female sexuality in late nineteenth-century art, medicine and literature. In H. L. Gates (Ed.), Race, writing and difference (pp. 223-259). Chicago: University of Chicago Press.

Gregory, D. (2003). Emperors of the gaze: Photographic practices and productions of space in Egypt, 1839-1914. In J. Ryan \& J. Schwartz (Eds.), Picturing place: Photography and the geographical imagination (pp. 195-225). London: I. B. Tauris. 
Guell, C., \& Ogilvie, D. (2015). Picturing commuting: Photovoice and seeking well-being in everyday travel. Qualitative Research, 15(2), 201-218.

Guell, C., Panter, J., Jones, N. R., \& Ogilvie, D. (2012). Towards a differentiated understanding of active travel behaviour: Using social theory to explore everyday commuting. Social Science \& Medicine, 75(1), 233-239.

Hannam, K., Sheller, M., \& Urry, J. (2006). Editorial: Mobilities, immobilities and moorings. Mobilities, 1(1), 1-22.

Harper, D. (2002). Talking about pictures: A case for photo elicitation. Visual Studies, 17(1), 1326.

Hein, J., Evans, J., \& Jones, P. (Eds.) (2008). Mobile methodologies: Theory, technology and practice. Geography Compass, 2(5), 1266-1285.

Hussain, T. M., \& Smith, J. F. (1999). Women's physical mobility in rural Bangladesh: The role of socio-economic and community factors. Contemporary South Asia, 8(2), 177-186.

Johnsen, S., May, J., \& Cloke. P. (2008). Imag(in)ing 'homeless places': Using auto-photography to (re)examine the geographies of homelessness. Area, 40(2), 194-207.

Johnson, G. A. (2011). A child's right to participation: Photovoice as methodology for documenting the experiences of children living in Kenyan orphanages. Visual Anthropology Review, 27(2), 141-161.

Kaplan, I. (2015). Teaching in the conflict zone: Indigenous mobile teacher trainers' photographs and narratives from the field, Karen State, Burma. In S. Miles \& A. Howes (Eds.), Photography in educational research: Critical reflections from diverse contexts (pp. 153167). New York: Routledge.

Kearns, M. B., (2000). Seeing is believing is knowing: Towards a critique of pure vision. Geographical Research, 38(3), 332-340.

Khalid, M. M. (2011). History of the Karakoram Highway. Rawalpindi: Hamza Pervez Printers.

Kohon, J., \& Carder, P. (2014). Exploring identity and aging: Auto-photography and narratives of low income older adults. Journal of Aging Studies, 30, 47-55.

Kothari, U. (2001). Power, knowledge and social control in participatory development. In B. Cooke \& U. Kothari (Eds.), Participation: The new tyranny (pp. 139-152). London: Zed Books.

Kreutzmann, H. (1991). The Karakoram highway. Modern Asian Studies, 25, 711-736.

Larsen, J., Urry, J., \& Axhausen, K. (2006). Mobilities, networks, geographies. Aldershot: Ashgate.

Lewis, R. (1996). Gendering orientalism: Race, femininity and representation. London: Routledge

Lombard, M. (2013). Using auto-photography to understand place: Reflections from research in urban formal settlements in Mexico. Area, 45(1), 23-32.

Lorimer, J. (2010). Moving image methodologies for more-than-human geographies. Cultural Geographies, 17(2), 237-258.

Lutz, C., \& Collins, J. L. (1993). Reading National Geographic. Chicago: University of Chicago Press.

Manderscheid, K. (2014). Criticizing the solitary mobile subject: Researching relational mobilities and reflecting on mobile methods. Mobilities, 9(2), 188-219.

Mandleco, B. (2013). Research with children as participants: Photo elicitation. Journal of Pediatric Nursing, 18(1), 78-82.

Mannay, D. (2010). Making the familiar strange: Can visual research methods render the familiar setting more perceptible? Qualitative Research, 10(1), 91-111.

McIntyre, A. (2003). Through the eyes of women: Photovoice and participatory research as tools for reimagining place. Gender, Place \& Culture, 10(1), 47-66.

Medina, J. (2012). Hermeneutical injustice and polyphonic contextualism: Social silences and shared hermeneutical responsibilities. Social Epistemology, 26(2), 201-220.

Merriman, P. (2014). Rethinking mobile methods. Mobilities, 9(2), 167-187.

Murray, L. (2009). Looking at and looking back: Visualization in mobile research. Qualitative Research, 9(4), 469-488.

Packard, J. (2008). 'I'm gonna show you what it's really like out here': The power and limitation of participatory visual methods. Visual studies, 23(1), 63-77. 
Padgett, D. K., Smith, B. T., Derejko, K. S., Henwood, B. F., \& Tiderington, E. (2013). A picture is worth...? Photo elicitation interviewing with formerly homeless adults. Qualitative Health Research, 23(11), 1435-1444.

Phillips, A. (2005). Cultural geographies in practice: Walking and looking. Cultural Geographies, 12(4), 507-513.

Phoenix, C. (2010). Auto-photography in aging studies: Exploring issues of identity construction in mature body builders. Journal of Aging Studies, 24(3), 167-180.

Pink, S. (2008). An urban tour: The sensory sociality of ethnographic placemaking. Ethnography, 9(2), 175-196.

Pratt, M. L. (1994). Transculturation and autoethnography: Peru, 1615/1980. In F. Barker, P. Hulme, \& M. Iversen (Eds.), Colonial discourse/postcolonial theory (pp. 24-46). Manchester: Manchester University Press.

Pratt, M. L. (1992). Imperial eyes: Travel writing and transculturation. London: Routledge.

Pratt, M. L. (1999). Apocalypse in the Andes. Americas 51(4), 38-47.

Rose, G. (2007). Visual methodologies: An introduction to the interpretation of visual materials. London: Sage.

Schneiderman, S. B. (2013). Himalayan border citizens: Sovereignty and mobility in the NepalTibetan Autonomous Region (TAR) of China border zone. Political Geography, 35, 25-36.

Sensoy, O. (2011). Picturing oppression: Seventh graders' photo essays on racism, classism and sexism. International Journal of Qualitative Studies in Education, 24(3), 323-342.

Shah, P. (2015). Spaces to speak: Photovoice and the reimagination of girls' education in India. Comparative Education Review, 59(1), 50-74.

Shankar, A. (2016). Auteurship and image-makking: A (gentle) critique of the photovoice method. Visual Anthropology Review, 32(2), 157-166.

Sheller, M. (2011). Mobility. Sociopedia.isa. pp. 1-12. Retrieved from www.sagepub.net/isa/admin/viewPDF.aspx?\&art=Mobility.pdf

Sheller, M., \& Urry, J. (2006). The new mobilities paradigm. Environment and Planning A, $38(2), 207-226$.

Spinney, J. (2015). Close encounters? Mobile methods, (post)phenomenology and affect. Cultural Geographies, 22(2), 231-246.

Spinney, J. (2011). A chance to catch a breath: Using mobile video ethnography in cycling research. Mobilities, 6(2), 161-182.

Spinney, J. (2009). Cycling the city: Movement, meaning and method. Geography Compass, 3(2), 817-835.

Spivak, G. C. (1999). A critique of postcolonial reason. Cambridge, MA: Harvard University Press.

Streng, J. M., Rhodes, S. D., Ayala, G. X., Eng, E., Arceo, R., \& Phipps, S. (2004). Realidad latina: Latino adolescents, their school, and a university use photovoice to examine and address the influence of immigration. Journal of Interprofessional Care, 18(4), 403-415.

Sur, M. (2013). Through metal fences: Material mobility and the politics of transnationality at borders. Mobilities, 8(1), 70-89.

Thomas, M. (2009). Auto-photography. In R. Kitchin \& N. Thrift (Eds.), International encyclopaedia of human geography (pp. 244-251). London: Elsevier.

Urry, J. (2007). Mobilities. London: Polity Press.

Wang, C. C. (2006). Youth participation in photovoice as a strategy for community change. Journal of Community Practice, 14(1-2), 147-161.

Warren, S. (2017). Pluralising the walking interview: Researching (im) mobilities with Muslim women. Social \& Cultural Geography, 18(6), 786-807.

Wood, G., \& Malik, A. (2006). Sustaining livelihoods and overcoming insecurity. In G. Wood, A. Malik \& S. Sagheer (Eds.), Valleys in transition: Twenty years of AKRSP's experience in northern Pakistan (pp. 54-119). Oxford: Oxford University Press.

Zehle, J. (2015). Investigating life stories: The photovoices of young people with disabilities in northern Ethiopia. In S. Miles \& A. Howes (Eds.), Photography in educational research: Critical reflections from diverse contexts (pp. 21-35). New York: Routledge. 